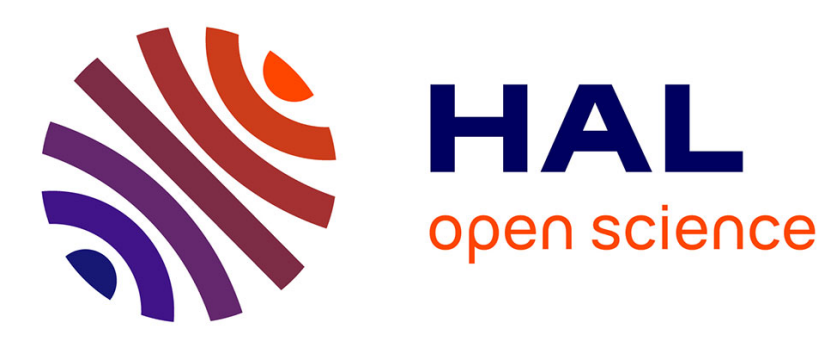

\title{
ICARE-VEG: A 3D physics-based atmospheric correction method for tree shadows in urban areas
}

K.R.M. Adeline, X. Briottet, X. Ceamanos, T. Dartigalongue, Jean-Philippe Gastellu-Etchegorry

\section{- To cite this version:}

K.R.M. Adeline, X. Briottet, X. Ceamanos, T. Dartigalongue, Jean-Philippe Gastellu-Etchegorry. ICARE-VEG: A 3D physics-based atmospheric correction method for tree shadows in urban areas. ISPRS Journal of Photogrammetry and Remote Sensing, 2018, 142, pp.311-327. 10.1016/j.isprsjprs.2018.05.015 . hal-01835698

\section{HAL Id: hal-01835698 https://hal.science/hal-01835698}

Submitted on 11 Jul 2018

HAL is a multi-disciplinary open access archive for the deposit and dissemination of scientific research documents, whether they are published or not. The documents may come from teaching and research institutions in France or abroad, or from public or private research centers.
L'archive ouverte pluridisciplinaire HAL, est destinée au dépôt et à la diffusion de documents scientifiques de niveau recherche, publiés ou non, émanant des établissements d'enseignement et de recherche français ou étrangers, des laboratoires publics ou privés. 


\section{ICARE-VEG: A 3D PHYSICS-BASED ATMOSPHERIC CORRECTION METHOD}

2 FOR TREE SHADOWS IN URBAN AREAS

3

4 K.R.M. Adeline ${ }^{\mathrm{ab}}$, X. Briottet ${ }^{\mathrm{a}}$, X. Ceamanos ${ }^{\mathrm{a} 1}$, T. Dartigalongue ${ }^{\mathrm{a}}$, J.-P. Gastellu-Etchegorry ${ }^{\mathrm{c}}$ 5

${ }^{a}$ The French Aerospace Lab (ONERA), 31055 Toulouse, France

${ }^{\mathrm{b}}$ University of Toulouse, Higher Institute of Aeronautics and Space (ISAE), 31055 Toulouse, France

${ }^{c}$ Centre for the Study of the Biosphere from Space (CESBIO), 31401 Toulouse, France

E-mail address of corresponding author: karine.adeline@ onera.fr

\section{KEYWORDS}

atmospheric correction,

radiative transfer,

hyperspectral,

high spatial resolution,

tree shadows,

urban areas

\section{ABSTRACT}

Many applications dedicated to urban areas (e.g. land cover mapping and biophysical properties estimation) using high spatial resolution remote sensing images require the use of 3D atmospheric correction methods, able to model complex light interactions within urban topography such as buildings and trees. Currently, one major drawback of these methods is their lack in modelling the radiative signature of trees (e.g. the light transmitted through the tree crown), which leads to an over-estimation of ground reflectance at tree shadows. No study has been carried out to take into account both optical and structural properties of trees in the correction provided by these methods. The aim of this work is to improve an existing 3D atmospheric correction method, ICARE (Inversion Code for urban Areas Reflectance Extraction), to account for trees in its new version, ICARE-VEG (ICARE with VEGetation).

\footnotetext{
${ }^{1}$ Present address : CNRM, Météo-France/CNRS, 31057 Toulouse, France
} 
After the execution of ICARE, the methodology of ICARE-VEG consists in tree crown delineation and tree shadow detection, and then the application of a physics-based correction factor in order to perform a tree-specific local correction for each pixel in tree shadow. A sensitivity analysis with a design of experiments performed with a 3D canopy radiative transfer code, DART (Discrete Anisotropic Radiative Transfer), results in fixing the two most critical variables contributing to the impact of an isolated tree crown on the radiative energy budget at tree shadow: the solar zenith angle and the tree leaf area index (LAI). Thus, the approach to determine the correction factor relies on an empirical statistical regression and the addition of a geometric scaling factor to account for the tree crown occultation from ground. ICARE-VEG and ICARE performance were compared and validated in the Visible-Near Infrared Region (V-NIR: 0.4-1.0 $\mu \mathrm{m}$ ) with hyperspectral airborne data at $0.8 \mathrm{~m}$ resolution on three ground materials types, grass, asphalt and water. Results show that (i) ICARE-VEG improves the mean absolute error in retrieved reflectances compared to ICARE in tree shadows by a multiplicative factor ranging between 4.2 and 18.8, and (ii) reduces the spectral bias in reflectance from visible to NIR (due to light transmission through the tree crown) by a multiplicative factor between 1.0 and 1.4 in terms of spectral angle mapper performance. ICARE-VEG opens the way to a complete interpretation of remote sensing images (sunlit, shade cast by both buildings and trees) and the derivation of scientific value-added products over all the entire image without the preliminary step of shadow masking.

\section{Introduction}

The potential of hyperspectral remote sensing imagery with high spatial resolution in the reflective domain $0.4-2.5 \mu \mathrm{m}$ has long been studied to increase the characterization of surface materials for ecosystem monitoring (Wulder et al., 2004), and particularly for urban environments (Jensen and Cowen, 1999; Small, 2001; Puissant and Weber, 2014), such as for vegetation biodiversity assessment (Alonzo et al., 2014), road traffic monitoring (Rosenbaum et al., 2010) and land cover classification (Roessner et al., 2001). For urban applications, one major limitation comes from the complex topography of urban landscapes combined with low solar elevation, which induces many shaded pixels in aerial and satellite images at high spatial resolution. In image processing, shaded region areas are often neglected, with shadows classified as a material class (Dell'Acqua et al., 2005; Yuan and Bauer, 2006) or used to retrieve the dimensions of nearby buildings (Liow and Pavlidis, 1990). 
The processing of shadows involves both shadow detection (Adeline et al., 2013a) and shadow correction (Shahtahmassebi et al., 2013). For shadow correction purposes, two main categories of methods can be examined. The first includes de-shadowing methods using multisource data fusion or applying a radiometric enhancement correction to "re-light" shaded pixels generally based on histogram adaptation strategies (Dare, 2005). Although sufficient for coarse classification of urban material types, it is unsatisfactory for the intra-class variability quantification and the retrieval of physico-chemical properties of surface materials, which requires the accurate spectral reflectance of each material. The second category of deshadowing methods uses atmospheric correction codes to convert at-sensor radiance into reflectance units. They are physics-based methods which correct the radiometrical bias occurring in shaded pixels by considering atmospheric conditions and sometimes the scene 3D topography (e.g. Digital Surface Model - DSM or a vector model). To our knowledge, only a few atmospheric correction codes are adapted to urban environments: the semiempirical model of Chen et al., 2013, ICARE (Inversion Code for urban Areas Reflectance Extraction, Lachérade et al., 2008) and ATCOR-4 (Atmospheric/topographic correction for airborne imagery, Richter and Schläpfer, 2002). However, only the two last codes can achieve an exact calculation of the 3D radiative terms to retrieve surface reflectance.

ATCOR-4 is currently the most used atmospheric correction code by the scientific community that has been tested for a large panel of hyperspectral airborne sensors over the spectral range $0.4-2.5 \mu \mathrm{m}$. For a flat terrain composed of lambertian materials (i.e. corresponding to an isotropic light reflection), ATCOR-4 performance achieves an error in the retrieved reflectance of 0.02 and 0.04 for an initial reflectance of less than 0.10 and 0.40 , respectively (Rese ATCOR-4 User Guide; Richter and Schläpfer, 2002). For a rugged terrain, ATCOR-4 performance is not quantified since it strongly depends on the DSM accuracy and the registration between the image and the DSM (Rese ATCOR-4 User Guide; Schläpfer et al., 2000). An improved version of ATCOR named BREFCOR is able to correct the effects of bidirectional reflectance distribution function of materials (Schläpfer et al., 2015). ICARE is a 3D atmospheric correction method dedicated to urban areas with lambertian materials. It was initially developed to process airborne multispectral images acquired by the PELICAN image system (Duffaut and Deliot, 2005) with spectral bandwidth of 30nm at a spatial resolution of $20 \mathrm{~cm}$, and with limited spatial extent. Its performance showed a maximum peak to peak accuracy of 0.04 in the retrieved reflectance for eight spectral bands from 420 to $917 \mathrm{~nm}$ and for pixels located in shadows cast by buildings (Lachérade et al., 2008). Currently, ICARE is being improved to process hyperspectral images. The improved method named ICARE-HS 
100 (ICARE using HyperSpectral imagery) was tested with airborne HySpex hyperspectral data

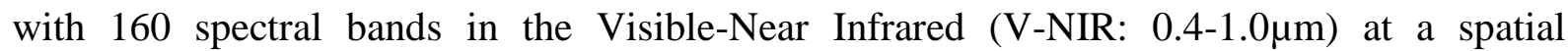
resolution of $80 \mathrm{~cm}$ (Ceamanos et al., 2017). The performance of this new ICARE version was not quantitatively validated.

Atmospheric correction codes succeed in modeling opaque objects governed by absorption and reflection processes (e.g. buildings). However, the main issue lies in the lack of modeling of transmittance processes resulting from semi-transparent and transparent surfaces (e.g. trees and windows). For trees, ATCOR-4 and ICARE neglect the fraction of the incident solar radiation that is transmitted through tree crown, thus generating a bias in the retrieved reflectance in tree shadows (Adeline et al., 2012; Schläpfer et al., 2013; Damm et al, 2015). Actually, the under-estimation of total irradiance in the shade produces an overestimation of retrieved reflectance, which is higher in the NIR bands than in the visible with a transition close to the red-edge (Adeline et al., 2012; Damm et al, 2015). With ICARE, Adeline et al., 2012 showed that the retrieved reflectance in tree shadows compared to their counterpart in sunlit areas for the same material type (asphalt and grass) gave mean root mean square error values up to 0.09. With ATCOR-4, Damm et al, 2015 showed that an inaccurate estimation of irradiance can lead to a difference in tree shadows in NDVI values (Normalized Difference Vegetation Index; Rouse, 1974) up to $13 \%$ and in PRI values (Photochemical Reflectance Index; Gamon et al., 1992) up to $32 \%$ for some test scenarios over grass. One of the required steps to solve this issue is to carry out a sensitivity analysis in order to know which tree canopy parameters, both spectral (e.g. optical properties of leaves and wood) and structural (e.g. leaf area index, leaf angular distribution, clumping, tree dimensions) have the most impact on light transmission through the tree crown. To our best knowledge, such an analysis has not been performed yet for radiative transfer budget estimation.

The objective of this work is to improve the existing 3D atmospheric correction code ICARE to cope with the presence of trees. The new version is further named ICARE-VEG (ICARE with VEGetation). It is based on the building of a physics-based correction factor to apply to ICARE's outputs in order to provide a better estimation of surface reflectance in tree shadows. The challenge is to define a general correction baseline adapted to any urban trees and requiring a small number of relevant variables to study. To this end, ICARE-VEG relies on the decoupling between a spectral reference correction based on a "reference tree model" with fixed geometrical dimensions, and a spatial correction accounting for the real dimensions of the tree processed in the image. The spectral reference correction is built from the results of a sensitivity analysis based on a design of experiments to derive the most important factors 
134 contributing to light transmission through the tree crown. The spatial correction factor is

computed from the tree dimensions and the location of the pixel within the tree shadow. At last, ICARE-VEG only considers deciduous trees with green healthy leaves and surfaces with a lambertian spectral behaviour. 


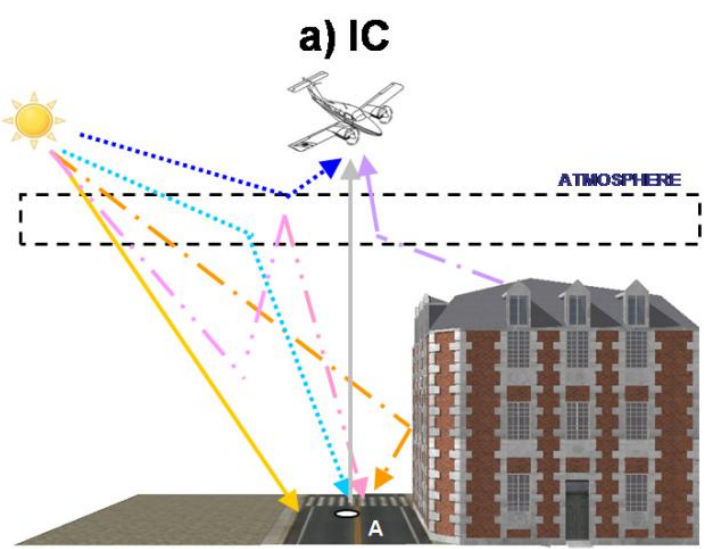

c) ICV

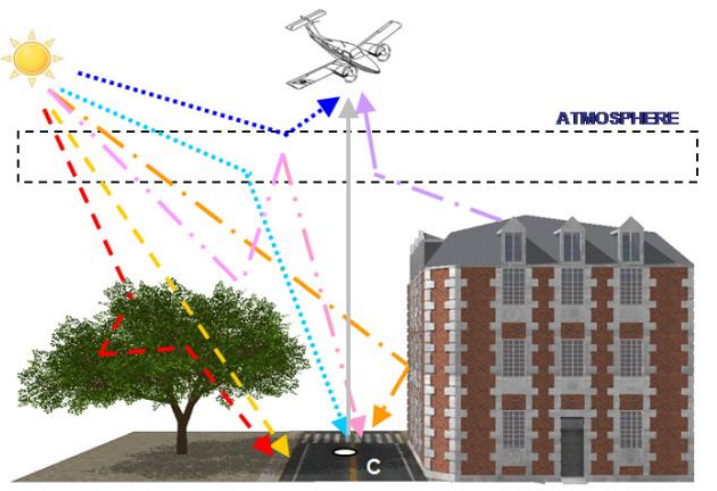

b) IC

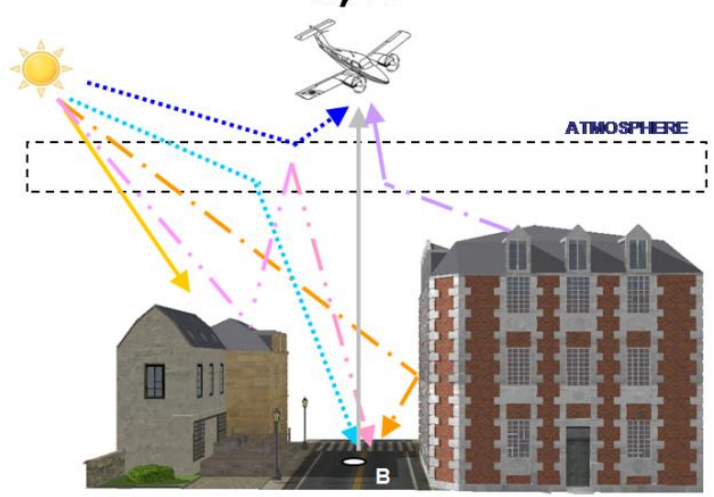

IRRADIANCES

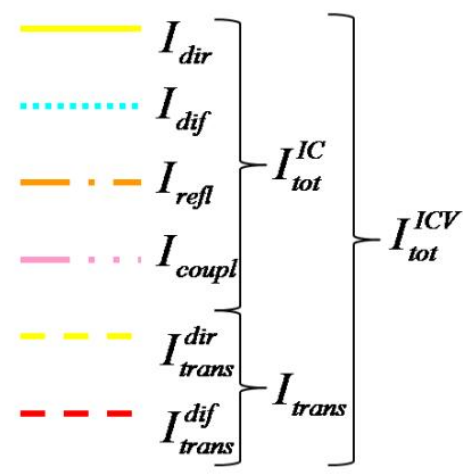

\section{RADIANCES}

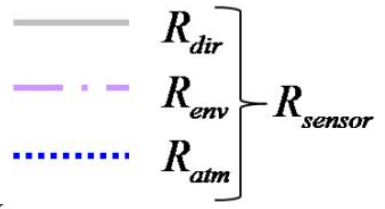

Fig. 1. Taxonomy of the radiative transfer components for ICARE (IC) and ICARE-VEG (ICV) for an urban scene and for a target a) in the sun, b) in a building shadow and c) in a tree shadow.

In urban environment, the radiative components $R_{\text {dir }}$ and $I_{\text {tot }}$ are highly sensitive to the complex 3D topography inducing downwelling and upwelling multiple reflections on surrounding surface elements, and to local atmospheric multiple scattering. The total at-sensor radiance, , is the sum of the direct radiance, , the environment radiance due to the atmospheric light scattering, , and the atmospheric radiance (the so-called path radiance),

(Fig. 1). Also, the total irradiance, , is the sum of the direct solar irradiance, $I_{\text {dir }}$, the atmospheric diffuse solar irradiance, , the irradiance due to scattering by the surrounding environment, , and the earth-atmosphere coupling irradiance, $I_{\text {coupl }}$ (Fig. 1).

ICARE (noted IC) considers that surfaces have lambertian reflectances and the viewing direction is Nadir. The surface spectral bidirectional reflectance for any pixel $P$ at the wavelength $\lambda$ is simply named $\rho(P, \lambda)$. ICARE analytically determines the surface reflectance for a pixel $A$ in a sunlit region (Fig. 1a) with: 
For a pixel $B$ in any shaded region (Fig. 1b), ICARE assumes to be null, leading to the following expression:

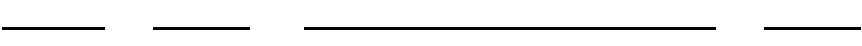

with

is only valid for shadows cast by opaque surface materials such as buildings. In shaded regions cast by trees, however, the incoming light transmitted through tree crowns, , must be considered in addition to (Fig. 1c). The term can be split into , the light directly transmitted without interactions with the tree elements, and , the light that is transmitted after at least one scattering with crown elements, either leaves or woody stems (Fig. 1c). Consequently, Eq. 3 needs to be modified for a pixel $C$ in tree shadow with a more accurate estimation of total irradiance received at ground, , such as :

crown that casts the shadow is seen from any pixel $C$ in the shadow. The analytical determination of $\beta$ is not straightforward due to both the spectral and spatial dependence of 
the ratio

. Here, the main assumption is that the spectral and spatial response of can be linearly decorrelated. Thus, $\beta$ is decomposed as follows:

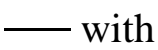

is the mean spectral response of according to a "reference tree model" with fixed geometric dimensions. is further called the reference correction factor. It is associated with a reference solid angle . . is the solid angle at the location of the pixel $C$ for the real geometrical dimensions of the tree in the scene.

\section{ICARE-VEG method implementation}

The semi-automatic ICARE-VEG correction code is structured as depicted in Fig. 2. 215 The original ICARE code is executed as a preliminary step (section 3.1). Individual trees and their associated shadows are then identified to perform a tree-specific local correction for each 217 pixel in tree shadow (sections 3.2 and 3.3). The physics-based correction factor $\beta$ (section 3.4) 218 is divided into the determination of the reference correction factor (section 3.4.1) and the 219 solid angles, and (section 3.4.2). is evaluated in 3 steps. They rely on a 220 "reference tree model" with fixed geometrical dimensions to study how is impacted by 221 tree crown biophysical and structural variables, and other external variables. For that purpose, 222 the DART 3D radiative transfer code is used to simulate light interactions within a tree crown 223 (Discrete Anisotropic Radiative Transfer; Gastellu-Etchegorry et al, 1996). The results are 224 stored in a look-up table and a sensitivity analysis aims at defining the major variables required to assess (section 3.4.1.1). Then, these major variables are derived from the processed image (section 3.4.1.2) and they are used to empirically compute thanks to statistical multivariate strategies (section 3.4.1.3). At last, ICARE-VEG correction provides an improved reflectance retrieval for the pixels in tree shadows, while pixels in the sun and in 229 the shadow of buildings are not updated from ICARE outputs (section 3.5). 


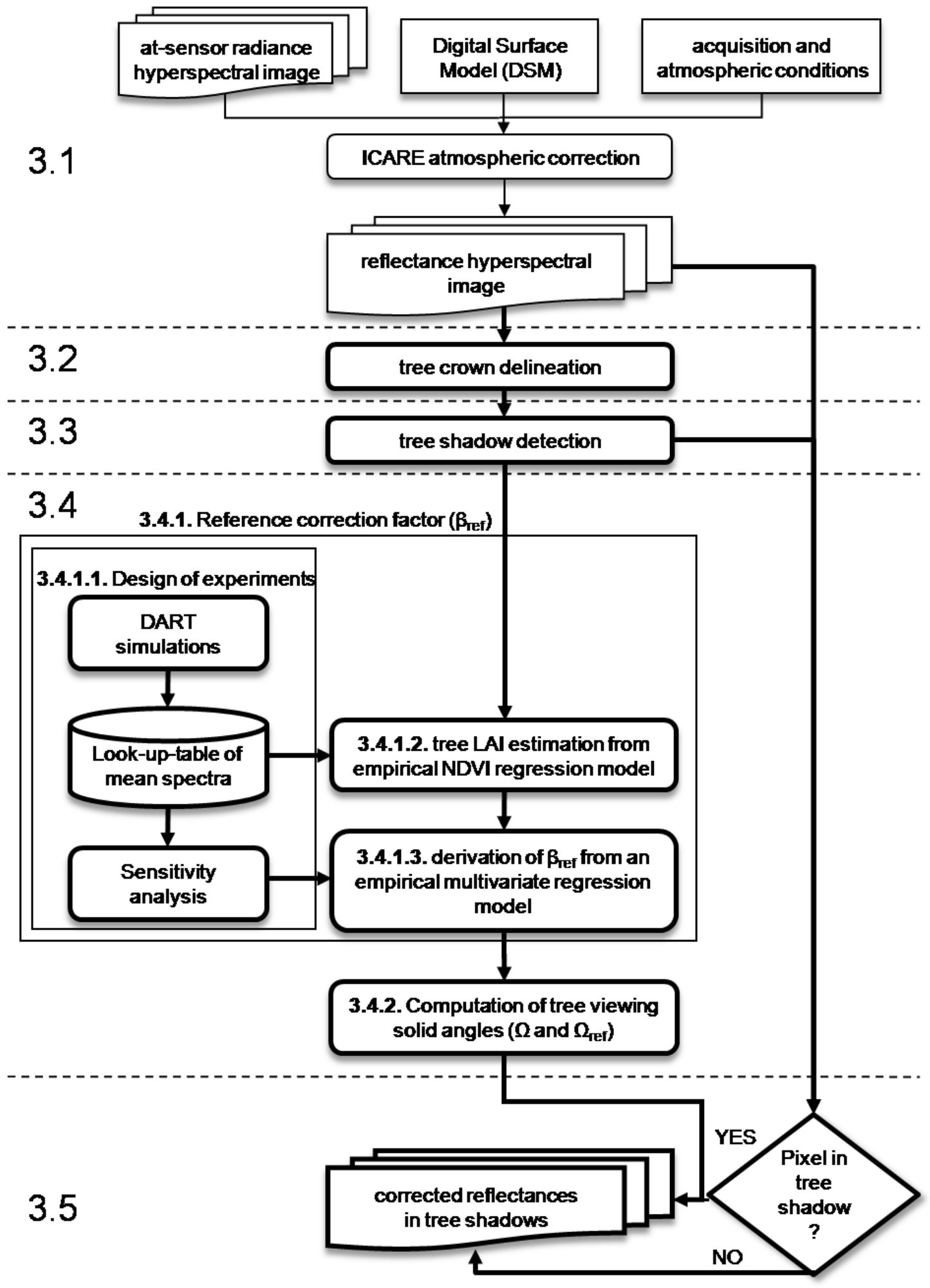

Fig. 2. ICARE-VEG method workflow (3.1 existing ICARE method, from 3.2 to 3.5 new developments presented in this paper, highlighted by bold boxes). 
ICARE (Lachérade et al., 2008) requires 3 inputs: an at-sensor image expressed in

spectral radiance unit, a DSM and the geometry conditions (e.g. flight altitude, sensor spatial and spectral characteristics, sun and viewing angles) and the atmospheric conditions. Atmospheric radiative components are computed with the radiative transfer code 6SV (Vermote et al., 1997). The output is an image of spectral surface reflectance.

\subsection{Tree crown delineation}

Two consecutive image segmentations are performed for delineating the individual tree crowns: detection of tree clusters, and separation of individual tree crowns in each cluster (Fig. 3).

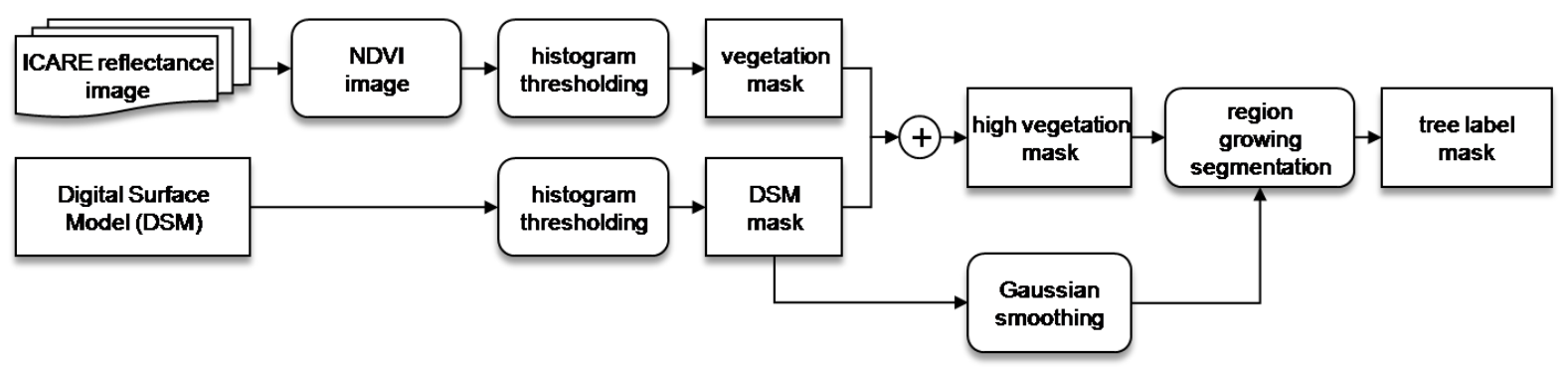

Fig. 3. Flowchart of the individual tree crown delineation.

First, pixels of vegetation are extracted in the image by computing the NDVI with the red band at $670 \mathrm{~nm}$ and the NIR band at $800 \mathrm{~nm}$. The histogram of the NDVI image is thresholded with the bimodal technique of Otsu (1979) to create a binary vegetation mask. Then, a refinement step uses the DSM to separate high vegetation (e.g. trees) and low vegetation (e.g. grass). The histogram of the DSM image is classified with a user-defined threshold based on the minimum tree height the user wants to consider. The overlap between the resulting DSM mask and the vegetation mask generates the high tree vegetation mask (i.e. tree clusters location).

Afterwards, individual tree crowns are delineated within each tree cluster. Zheng et al., 2016 give a relevant review of long studied techniques in the literature. The most used technique is rasted-based using extrapolation, interpolation and smoothing procedures for treetop detection and crown segmentation. First, the DSM mask is smoothed with a Gaussian filter in order to flatten the strong irregularities on top of tree canopies. Second, a region growing segmentation based on the method of Iovan et al. (2014) is used to delineate the tree 
crowns. In short, the method detects local maxima in the DSM from the high vegetation mask, attributes a tree label to each treetop, and then performs a gradient descent technique to give a tree label to all pixels in the high vegetation mask. This step provides a tree label mask.

To avoid the detection of several treetops for the same tree, an adjacency condition sets the minimum distance between two treetops. This distance, expressed in a number of pixels, essentially depends on the image spatial resolution. The tree label mask is refined with two other criteria. The first removes trees with very small crowns, using a minimum number of pixels per tree label. The second one eliminates tree crowns that are partially in the shade of other trees or buildings. For that, it uses a maximum percentage of shaded pixels for a tree crown.

\subsection{Tree shadow detection}

The identification of tree shadows is twofold: detection of all the shadows in the image and assignation of tree labels for tree shadows pixels (Fig. 4).

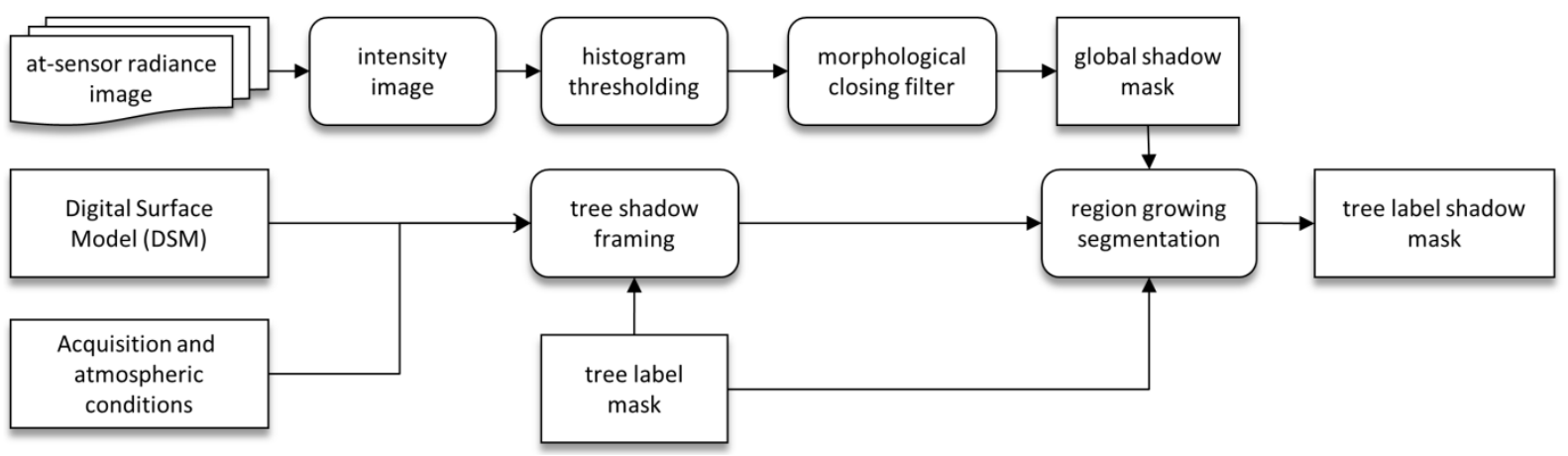

Fig. 4. Flowchart of the individual tree shadow detection.

First, the shadow mask is created using an intensity image (noted $I$ ) computed from the combination of four radiance $(R)$ spectral images $(B: 470 \mathrm{~nm}, G: 550 \mathrm{~nm}, R: 670 \mathrm{~nm}$ and NIR: 800nm):

$$
I=\frac{2 \times\left(R_{N I R}+R_{R}\right)+R_{B}+R_{V}}{6}
$$

A global shadow binary mask is derived from this intensity image by histogram thresholding following the first valley detection method of Nagao et al.(1979). This method has shown good performance for high spatial resolution aerial images (Adeline et al, 2013a). 
A morphological closing filter is applied in order to spatially homogenize the tree shadows possibly containing many penumbra areas.

Second, the detection of tree shaded pixels is achieved by framing each individual tree shadow with a rectangular box with vertices $P_{1}-P_{2}-P_{3}-P_{4}$ (Fig. 5a). The edge $P_{1}-P_{2}$ of this box represents the tree crown diameter, which is the segment intersecting the treetop in the direction perpendicular to the sun azimuth angle $\varphi_{s}$. The orientation of the adjacent edges of the box, namely $P_{2}-P_{3}$ and $P_{1}-P_{4}$, is driven by $\varphi_{s}$ while their length is dependent on the tree shadow length $L$ (Fig. 5a) following sun ray parallel projection to the ground (Rosskopf et al., 2017). This length $L$ is actually computed from the knowledge of the ground sampling distance (GSD), the sun zenith angle $\left(\theta_{s}\right)$, and the tree height $\left(H_{\text {tree }}\right)$ derived from the treetop position and the DSM:

$L=\frac{\tan \left(\theta_{S}\right) \times H_{\text {tree }}}{G S D}$

a) upper view

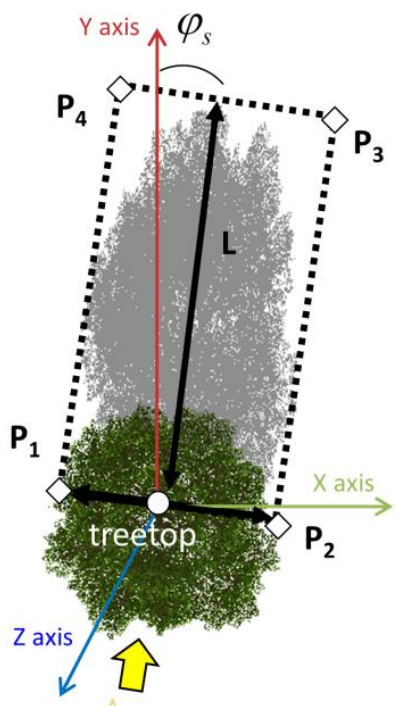

b) 3D view

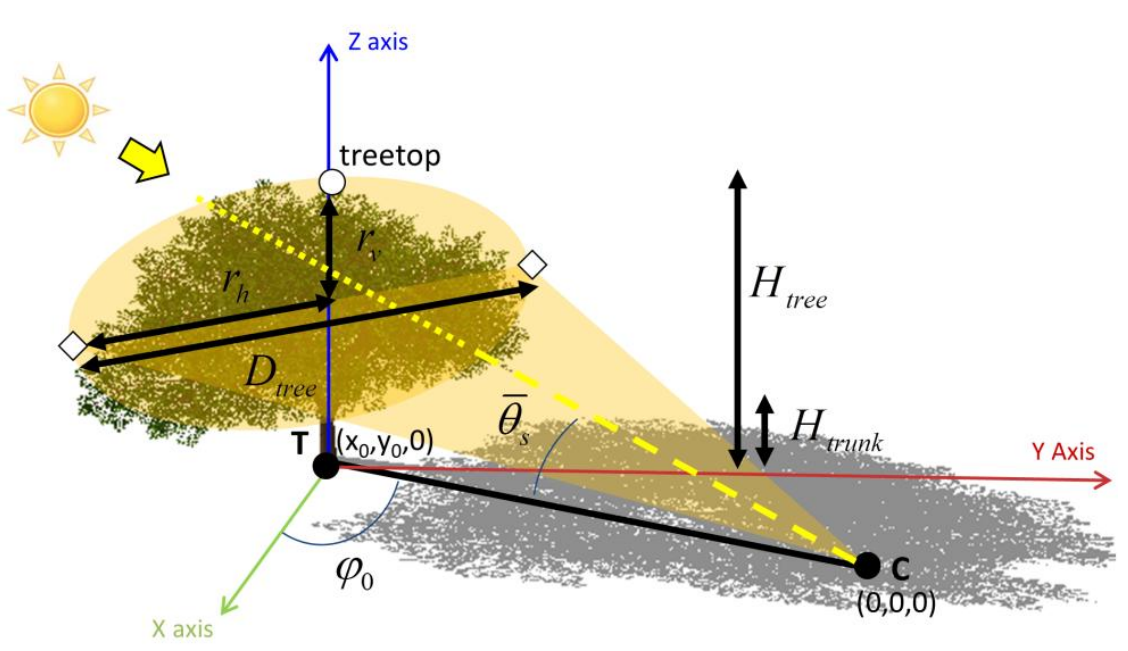

Fig. 5. Geometric configurations with an isolated tree for a) tree shadow framing and b) solid angle computation from a point $C$ in tree shadow and for a tree crown modelled as an ellipsoid (for the annotations see Appendix B).

Once the dimensions of the rectangular box are known, a region growing technique is applied, consisting in gradually scanning the box area and looking for pixels that belong to the global shadow mask but do not fall into the labeled pixels of the tree label mask. Each 
detected tree shaded pixel is assigned to the corresponding tree label to build a tree shadow label mask.

In case of overlapping tree shadows, the highest tree is assumed predominant over the others. Also, a shaded region cannot be associated with more than one tree. And a refinement step is applied to remove small tree shadows based on a criterion counting the number of pixels belonging to each tree label.

\subsection{Correction factor determination}

The correction factor $\beta$ is the product between the reference correction factor $\beta_{\text {ref }}$ (section 3.4.1) and a ratio of viewing solid angles $\Omega(C) / \Omega_{\text {ref }}$ (section 3.4.2; Eq. 6).

\subsubsection{Reference correction factor}

A regression model is built using a design of experiments based on a "reference tree model" for further empirical computation of $\beta_{\text {ref }}$.

\subsubsection{Design of experiments with DART and sensitivity analysis}

A simple scenario was considered in the form of an isolated tree on a flat ground, for urban mid-latitude conditions and considering a viewing direction at Nadir (Fig. 6). Table 1 gives the DART input parameters that describe the scene and the "reference tree model" (Gastellu-Etchegorry et al, 1996). The latter has fixed arbitrary dimensions, an ellipsoid crown, and a trunk outside and inside the crown with a cylindrical and conical shape, respectively. The DART spatial discretization scheme was set to $0.4 \mathrm{~m}$ (i.e. spatial resolution of the output image). 


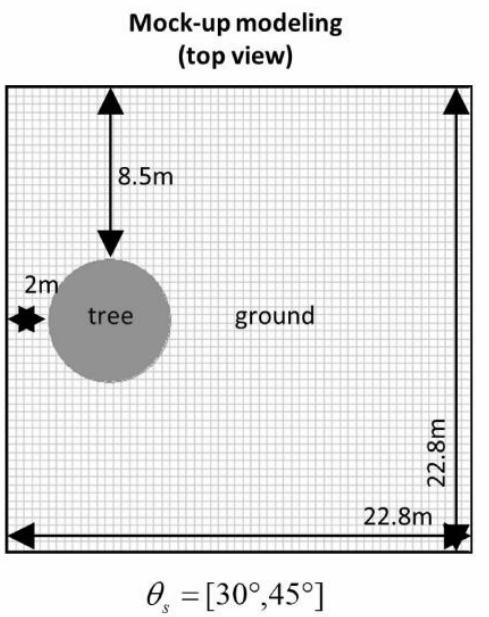

Table 1. DART settings for the design of experiments (the abbreviations of the variables of interest are given in brackets and in bold)

\begin{tabular}{|c|c|c|}
\hline & Variables [units] & Values \\
\hline \multirow{2}{*}{ Sun geometry } & Zenith angle $\left[{ }^{\circ}\right](\mathbf{S U N})$ & $30-45-60$ \\
\hline & Azimuth angle $\left[{ }^{\circ}\right]$ & 90 (relative value) \\
\hline Sensor geometry & Zenith angle $\left[{ }^{\circ}\right] /$ azimuth angle $\left[{ }^{\circ}\right]$ & $0 / 0$ \\
\hline \multirow{2}{*}{ Spectral bands } & Number ${ }^{\mathrm{a}} /$ Range $[\mu \mathrm{m}]$ & $110 / 0.4-1.0$ \\
\hline & FHWM $^{\mathrm{b}}[\mathrm{nm}]$ & 3.7 \\
\hline \multirow{3}{*}{$\begin{array}{l}\text { Atmospheric } \\
\text { conditions }\end{array}$} & Gaseous atmospheric profile & Mid-latitude summer \\
\hline & Aerosol type & Urban \\
\hline & Visibility [km] (VISI) & $10-23$ \\
\hline \multirow{6}{*}{ Scene } & Dimensions in $\mathrm{x}, \mathrm{y}, \mathrm{z}$ [m x m x m] & For a zenith angle $<60^{\circ}: 22.8 x$ \\
\hline & & $22.8 \times 14.0$ \\
\hline & & For a zenith angle $=60^{\circ}: 30.8 \mathrm{x}$ \\
\hline & & $30.8 \times 14.0$ \\
\hline & Voxel size in $\mathrm{x}, \mathrm{y}, \mathrm{z}$ [m x m x m] & $0.4 \times 0.4 \times 0.4$ \\
\hline & Ground reflectance (GROUND) & Asphalt and grass (cf. Fig.7) \\
\hline \multirow{3}{*}{ Isolated tree } & Tree height $[\mathrm{m}] /$ tree crown height $[\mathrm{m}]$ & $14.2 / 9.4$ \\
\hline & $\begin{array}{l}\text { Tree crown ellipsoid axis in } \mathrm{x}, \mathrm{y}[\mathrm{m} \mathrm{x} \\
\mathrm{m}]\end{array}$ & $6 \times 6$ \\
\hline & Trunk diameter below crown $[\mathrm{m}]$ & 0.4 \\
\hline
\end{tabular}


Tree leaf area index $\left[\mathrm{m}^{2} . \mathrm{m}^{-2}\right](\mathbf{L A I})$

Leaf angle distribution

Average leaf angle $\left[{ }^{\circ}\right](\mathbf{A L A})$

Horizontal random distribution of holes in the tree crown [\%]

\section{(POROSITY)}

Leaf optical properties (LOP)
$0.5-1-1.5-2-2.5-3-3.5-4$

$-6-8$

ellipsoidal

$30-57.58-70$

$0-30-70$

\section{$348{ }^{a}$ Spectral bands inside atmospheric water vapour windows are not considered}

$349{ }^{b}$ FHWM: Full-Half-Width-Maximum

In agreement with previous studies characterizing the canopy reflectance (Weiss et al., 2000; Combal et al., 2002) or the tree crown transmittance (Sampson and Smith, 1993), seven variables of interest $X$ are selected to study the variations of $\beta_{\text {ref }}$ : tree Leaf Area Index that is the product between Leaf Area Index of the scene and the vegetation cover of the scene (for simplicity referred in this paper as LAI; Norman and Welles, 1983), Average Leaf Angle (ALA) defined for an ellipsoidal angle distribution (Campbell, 1990), percentage of holes in the tree crown (POROSITY) approximating somehow the clumping effect, Leaf Optical Properties (LOP), ground reflectance (GROUND), sun zenith angle (SUN) and atmospheric visibility (VISI). Each variable is tuned between 2 and 10 values according to its sensitivity. The ground and trunk optical properties come from the DART spectral database while the leaf optical properties come from the ANGERS03 spectral database (Jacquemoud et al., 2003). The ground surface is assumed to be asphalt or grass (Fig. 7). Three representative urban tree species were chosen: liquidambar "liquidambar styraciflua", for its mean leaf optical properties, and oak "quercus palustris" and poplar "populus alba", for their extreme optical properties (Fig.7). 

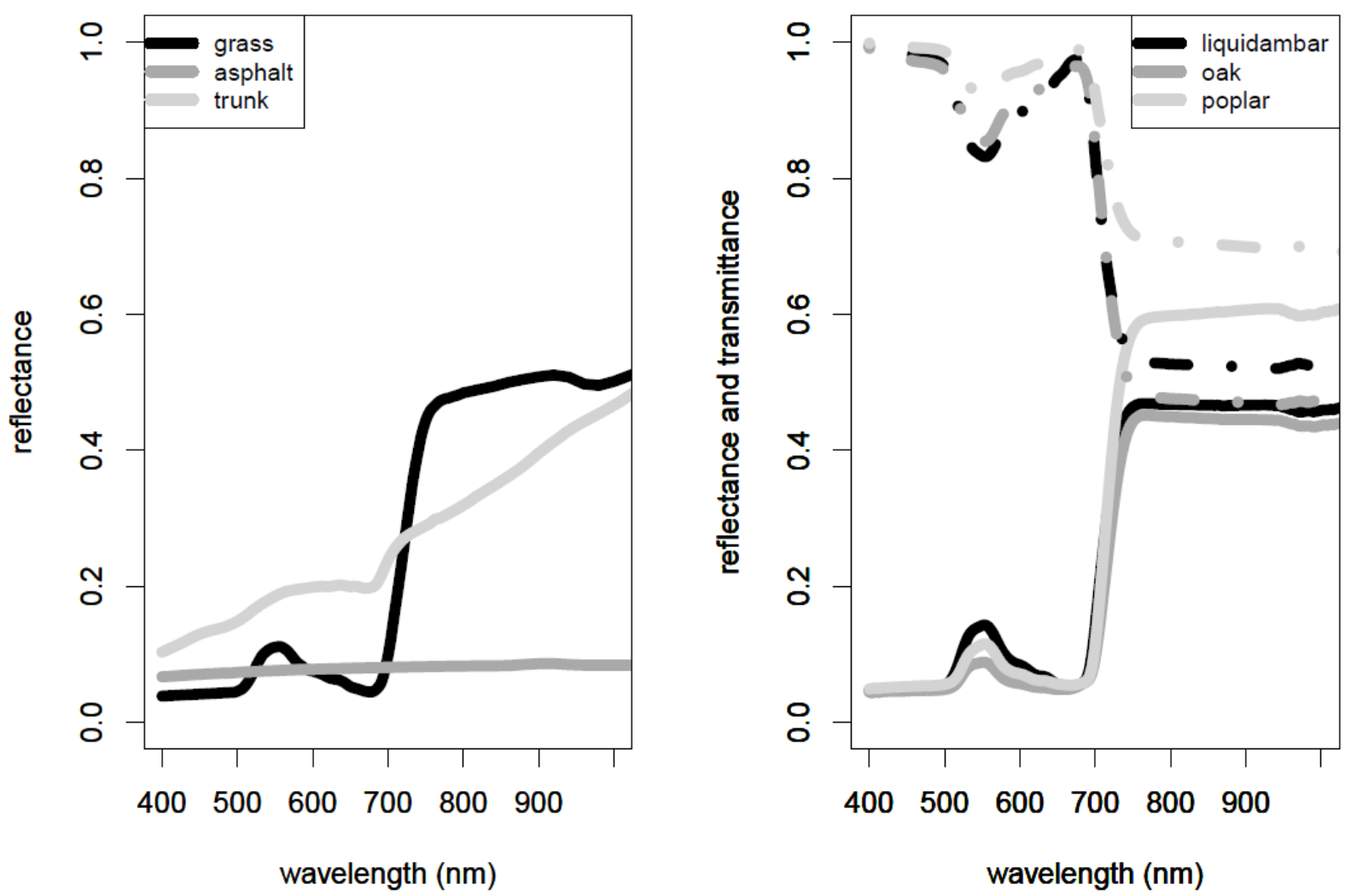

Fig. 7. Optical properties of scene components: two ground types (asphalt and grass) and trunk (left), leaves for the "reference tree model" (right: reflectances are in solid lines and transmittances are in dashed lines).

A full factorial design was carried out to study the impact of each independent variable $X$, individually or in interactions with the others, on the variations of (Droesbeke et al., 1997). DART simulated a total of 3240 scenarios, corresponding to top-of-canopy hyperspectral images with 110 spectral bands. It provided the radiative quantities required to compute per ground pixel in tree shadow. Mean values of were stored in a look-uptable and used to perform a global sensitivity analysis to find out the major variables $X^{\prime}$ for determining . A variance analysis (ANOVA) with a linear relationship between and the variables $X$ was performed to compute a sensitivity index noted $\eta^{2}$. This is the ratio "sum of squares values accounting for the single and combined effects of the variables on the variance of " over "total sum of square values" (Monod et al., 2006; Olejnik and Algina, 2003). SUN and LAI are the major variables $X^{\prime}$ because they give the highest values of (cf. Appendix A). SUN being usually known (e.g. from date, time and location), the issue is to estimate the LAI, which is therefore discussed below. 


\subsubsection{Tree LAI estimation}

Tree LAI can be estimated through the use of spectral vegetation indices from which NDVI is the most used (Colombo et al., 2003 ; Jensen et al., 2012). An empirical LAI-NDVI relationship is built based on a Beer-Lambert exponential regression model with 3 coefficients (Baret and Guyot, 1991):

$$
N D V I=N D V I_{\infty}+\left(N D V I_{g}-N D V I_{\infty}\right) \cdot \exp ^{-k_{N D V I} \times L A I}
$$

where $N D V I_{g}$ is the NDVI value for a bare soil (i.e. LAI equals zero), $N D V I_{\infty}$ is the asymptotic value of NDVI if LAI tends to infinite and $k_{N D V I}$ is the extinction coefficient.

The training data is provided by the design of experiments. For each DART scenario with a fixed LAI value, the NDVI is computed as the mean over a mask of $6 \times 6$ pixel grid centred at the canopy treetop. Then for each scenario out of the total of 324 run with DART, 10 pairs of LAI and NDVI are available. However, the estimation of the coefficients of the regression model in Eq.9 depends on the 6 remaining variables of $X$ from the design of experiments (ALA, POROSITY, LOP, GROUND, SUN, VISI). Except when SUN $=60^{\circ}$ (high solar incidence angle leading to odd fits), performance of the built regression models gave coefficients of determination $R^{2}>0.87$ and root mean square errors $R M S E<0.37$ in the estimated LAI.

Then, regression models are applied in the NDVI image and the NDVI value for each tree is computed as a mean over a $3 \times 3$ pixel grid centred at the treetop (grid size can be chosen manually). In practice, due to the difficulty to have a priori knowledge about the variable values (ALA, POROSITY, LOP, GROUND, SUN, VISI) for each tree, they are arbitrarily fixed to their average values : ALA $=57^{\circ}$ (close to the common spherical distribution), POROSITY $=0 \%$ (uniform leaf spatial distribution), LOP = liquidambar, GROUND $=$ asphalt, $\mathrm{SUN}=45^{\circ}$ and VISI $=23 \mathrm{~km}(\operatorname{good}$ visibility $)$.

\subsubsection{Multivariate regression analysis}

From the previously determined major variables $X^{\prime}$ (i.e. SUN and LAI), a multivariate linear regression model is built to estimate the reference correction factor $\beta_{\text {ref }}$ by using a 
stepwise strategy in order to decrease the number of terms in the regression expression

(Burnham and Anderson, 2004). A second degree polynomial expression with first order interactions between $X^{\prime}$ (LAI, SUN) is chosen at first. After some tests, the following reduced equation was chosen for all spectral bands:

$$
\begin{aligned}
& Y(\lambda)=a_{0}+X_{1}^{\prime} \cdot\left(a_{1}+a_{2} \cdot X_{1}^{\prime 2}+a_{3} \cdot X_{1}^{\prime 3}\right)+X_{2}^{\prime} \cdot\left(a_{4}+a_{5} \cdot X_{2}^{\prime}\right)+a_{6} \cdot X_{1}^{\prime} \cdot X_{2}^{\prime}++a_{7} \cdot X_{2}^{\prime} \cdot X_{1}^{\prime 2}+ \\
& a_{8} \cdot X_{1}^{\prime 2} \cdot X_{2}^{\prime 2} \\
& \text { with }\left\{\begin{array}{c}
X_{1}^{\prime}=e^{-0.5 . L A I} \\
X_{2}^{\prime}=\cos (S U N) \\
Y=\arcsin \left(\sqrt{\beta_{\text {ref }}}\right)
\end{array}\right.
\end{aligned}
$$

The 9 regression coefficients $a_{i}$ were bootstrapped over 1000 samples and their mean values were the coefficients of the final expression in Eq. 10. The confidence intervals for the bootstrap fit of Eq. 10 were: $0.87 \leq R^{2} \leq 0.93$ and $5.3 \% \leq R M S E \leq 8.3 \%(\mathrm{n}=2592)$. The estimated $\beta_{\text {ref }}$ corresponds to the ratio between $I_{\text {trans }}$ and $I_{\text {tot }}$ (Eq. 6). For instance for a sun zenith angle of $55^{\circ}$, its values reach more than $40 \%$, and have a monotonous increase towards NIR bands for very low LAI values (LAI $\leq 1$; Fig. 8). $I_{\text {trans }}$ is mainly dominated by the contribution of $I_{\text {trans }}^{\text {dir }}$ due to few light interactions with tree crown elements (Eq.4). The more the LAI increases, the more $\beta_{\text {ref }}$ values have a curvature at red-edge position between $700 \mathrm{~nm}$ and $800 \mathrm{~nm}$. This emphasizes the contribution of $I_{\text {trans }}^{\text {dif }}$ in addition to $I_{\text {trans }}^{\text {dir }}$ in $I_{\text {trans }}$. As a matter of fact, this spectrally-dependant feature of $\beta_{\text {ref }}$ is consistent with the leaves optical property features (Fig.7). Hence with the strong light multiple scattering within the tree crown, $\beta_{\text {ref }}$ values account less than $10 \%$ for very high LAI values (LAI $\geq 5$; Fig. 8). 

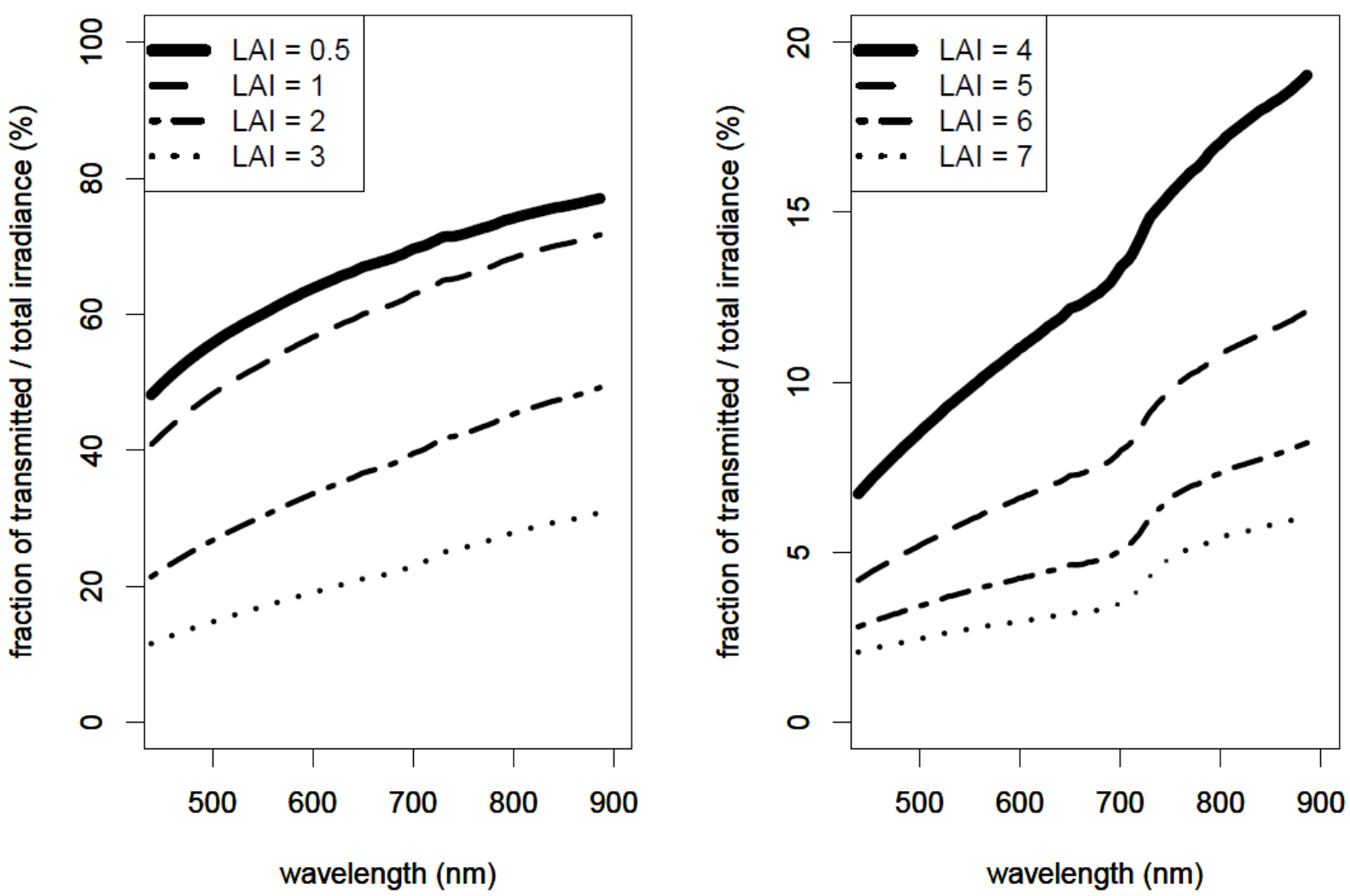

Fig. 8. Reference correction factor expressed in percentage (i.e. $\beta_{\text {ref }}$ ) for different LAI values and for a zenith angle of $55^{\circ}$.

\subsubsection{Tree viewing solid angle}

Once the reference correction factor $\beta_{\text {ref }}$ is estimated for each tree, a pixel-based spatial correction factor is needed to account for the real dimensions of the tree compared to the one used as a "reference tree model" in the design of experiments with DART. In a real scene, each point in the shade views a specific part of the tree; the closer the shaded point is to the tree position, and the larger the occultation is. This occultation is represented by the solid angle $\Omega$ under which the tree crown is seen. For simplicity, each tree crown is modelled as an elliptic shape (Fig. 5b). However, the mathematical expression of $\Omega$ is not straightforward and is further detailed in Appendix B. Then, the spatial correction factor is the ratio of $\Omega$ for the real tree in the image over $\Omega_{\text {ref }}$ for DART "reference tree model" (see Eq. 6). $\Omega$ values usually ranges between 0 and $\pi$ in steradian unit. $\Omega_{\text {ref }}$ equals to $0.4 \mathrm{sr}$.

\subsection{Tree shadow reflectance correction}


ICARE-VEG corrects the ICARE reflectance of any pixels in a tree shadow by a specific factor $\beta$ (see Eq. 6). Other pixels are not corrected. In order to compare ICARE and ICARE-VEG performances, the Mean Absolute Error (MAE) in retrieved reflectance in tree shadows, i.e. $\rho_{I C V}$, is compared with ground truth measurements when they are available, or ICARE sunlit retrieved reflectance of the same material type over another area, i.e. $\rho_{\text {ref } / I C}$, such as:

$M A E=\frac{1}{N} \times \sum_{i=0}^{N}\left|\rho_{I C V}\left(\lambda_{i}\right)-\rho_{\text {ref } / I C}\left(\lambda_{i}\right)\right|$

with $N$ the number of spectral bands.

The threshold for best MAE accuracy is set to 0.04 according to the performance of ICARE (Lachérade et al., 2008). A second metric is used, the spectral angle mapper (SAM; Kruse et al., 1993), to inform about the spectral distortions in the retrieved reflectance. It is a similarity spectral index independent of illumination and shadowing conditions. It requires computing the spectral angle $\alpha$ between the reference reflectance, i.e. $\rho_{\text {ref } / I C}$, and the retrieved reflectance, i.e. $\rho_{I C V}$ :

$\alpha=\cos ^{-1}\left(\frac{\sum_{i=1}^{N} \rho_{r e f / I C}\left(\lambda_{i}\right) \cdot \rho_{I C V}\left(\lambda_{i}\right)}{\left(\sum_{i=1}^{N} \rho_{r e f / I C}\left(\lambda_{i}\right)\right)^{1 / 2} \cdot\left(\sum_{i=1}^{N} \rho_{I C V}\left(\lambda_{i}\right)\right)^{1 / 2}}\right)$

The lower $\alpha$ value is, the more similar the spectral shape is between the reference and ICARE-VEG retrieved reflectances.

\section{Experimental data}

ICARE-VEG was validated by using the data collected on October $24^{\text {th }} 2012$ over Toulouse, France, from the UMBRA campaign (Urban Material characterization in the sun and shade of Built-up structures and trees and their Retrieval from Airborne image acquisitions over two French cities; Adeline et al., 2013b).

\subsection{Airborne hyperspectral data}


Airborne hyperspectral images were acquired with the push-broom sensor HySpexVNIR1600 (NorskElektroOptikk) with 160 bands in the spectral range $0.4-1 \mu \mathrm{m}$ and a spectral resolution of $3.7 \mathrm{~nm}$. For further analysis, 22 spectral bands are kept after removing low instrumental signal-to-noise ratio and water vapour atmospheric windows, and after spectral aggregation at $18 \mathrm{~nm}$ to be compatible with ICARE running with $6 \mathrm{SV}$ code. The acquisitions were at Nadir with a ground spatial resolution of $0.8 \mathrm{~m}$. In addition, a DSM was derived by multi-stereoscopic acquisitions from a panchromatic camera with a horizontal accuracy of $0.12 \mathrm{~m}$ (Pierrot-Deseilligny and Paparoditis, 2006). The aerial images were manually georeferenced based on the DSM. More than 20 ground control points were selected with the use of the ENVI software and the precision accuracy was inferior to the pixel size. At last, the images were radiometrically corrected with in-lab sensor calibration coefficients.

Three images were studied and extracted, namely image U1, U2 and U3 (Fig. 9). They corresponded respectively to an acquisition time of 12h40UTC for U1 and U2, and 11h30UTC for U3, with a solar zenith and azimuth angles of respectively $\left(57.2^{\circ} ; 198.1^{\circ}\right)$ for $\mathrm{U} 1$ and $\mathrm{U} 2$, and $\left(55.5^{\circ} ; 177.5^{\circ}\right)$ for $\mathrm{U} 3$. They induced large shadows on aerial images specifically in urban areas. The image U1 contains $27 \%$ of shaded pixels, $34 \%$ for U2, and finally $30 \%$ for U3. The images U1 and U2 are located on a sports centre, and are largely dominated by vegetated areas, both well maintained grass lawns and isolated trees, with sports infrastructures. They are characteristics of open areas whereas image U3 is oppositely representative of dense urban areas with high buildings and tree rows alongside the "canal du 510 Midi". 

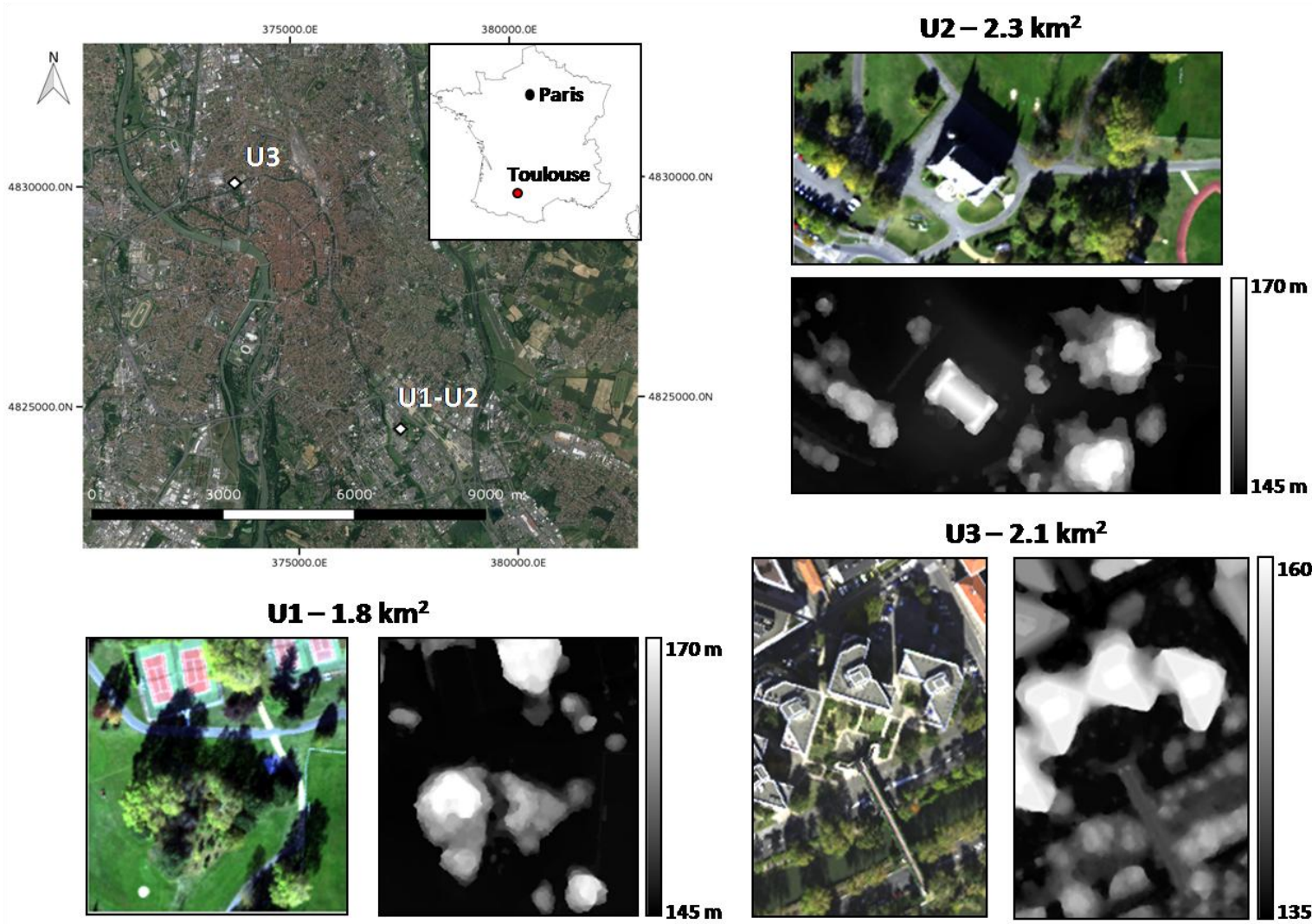

U3- $2.1 \mathrm{~km}^{2}$

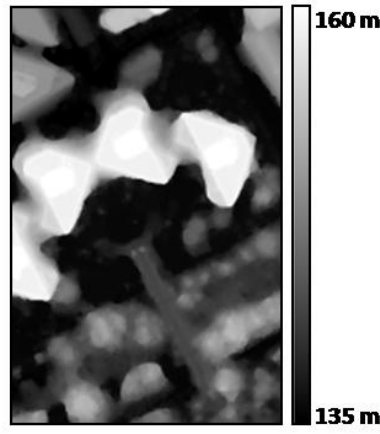

Fig. 9. RGB composite images used in this study associated with their greyscale DSM and their location on a Google Earth image over Toulouse, France.

\subsection{Field measurements and atmospheric conditions}

Road asphalt and grass surface reflectance were measured over the spectral range $0.35-1.0 \mu \mathrm{m}$ at $3 \mathrm{~nm}$ spectral resolution and $1 \mathrm{~nm}$ spectral sampling interval with a portable ASD (Analytical Spectral Devices Inc., Boulder, CO, USA) spectroradiometer and a reflectance plate Spectralon ${ }^{\circledR}$ of known reflectance. The integrated water vapor content and the aerosol type and abundance were measured with a microwave radiometer and a sunphotometer from AERONET (AErosol RObotic NETwork).

\section{Results and discussion}

ICARE-VEG is applied on the three images described in section 4. Results are 528 discussed for each processing step, then ICARE-VEG performance is compared with those of 529 ICARE in tree shadows and with ground truth. 
Tree crown delineation and tree shadow detection (sections 3.2 and 3.3, cf. Fig. 2) are the most critical steps in ICARE-VEG since a tree-specific correction is further applied accounting for each tree dimensions and position relatively to the location of the shaded pixels.

For tree crown delineation, the adjacency criterion was set to 5 pixels (i.e. $4 \mathrm{~m}$ ) for U2 and U3 images, and to 4 (i.e. $3.2 \mathrm{~m}$ ) for U1. The percentage of canopy pixels in the shade was set to $80 \%$ (except for $\mathrm{U} 3,70 \%$ ), the minimum number of pixels per tree to 40 pixels, and the tree minimum height to $5 \mathrm{~m}$. The DSM of U1 and U3 images was smoothed with a $2 \times 2$ size Gaussian filter. From the original images in Fig. 11a, results of NDVI images and histogram thresholding are shown in Fig. 10a and 10c, leading to the tree label masks shown in Fig. 11b. Some advantages and drawbacks can be pointed out:

(i) Vegetation detection with NDVI is often limited by changes in tree phenology, age and health (e.g. senescent leaves, diseases), and also by top of canopy anisotropic directional reflectance behavior. The UMBRA campaign took place at the early autumn season (Fig. 11a). Then, LAI of deciduous trees was falling, inducing a decrease in NDVI and sometimes tree under-detection (trees located at bottom of U1 and middle of U2 have mean NDVI values of 0.40 and 0.44, below the thresholds of 0.49 and 0.46: Fig.10c and Fig. 11b). Furthermore, the presence of a large vegetation fraction in the image (e.g. both grass and trees) produces an irregular shaped NDVI histogram, thus impacting the bimodal thresholding step (U1: Fig. 10c). As a perspective, a combination of vegetation spectral indices is recommended for a better discrimination with artificial materials (Iovan et al, 2014).

(ii) Topography is assumed to be flat, which induces tree misdetection when local variations occur (vegetated hedges on a bridge, U3: Fig. 11b). Moreover, DSM accuracy may be degraded next to sudden slope changes (lawn close to high buildings, U3:Fig. 11b). However, these errors are generally corrected during the shadow detection step, since no shadow is usually associated to the false detected trees (e.g. false detection of grass as trees).

(iii) The delineation of each tree crown is straightforward for isolated trees. For instance, good performances are achieved for trees in rows (left in U2 and along the canal in U3:Fig. 11b). Difficulties arise in presence of clustered trees (centre and top-left of U1 and on the right of U2, Fig. 11b) and pruned trees (middle-right of U3: Fig. 11b), sometimes due to 563 the presence of homogeneous canopies or a lack in height variation among trees (Zheng et al., 564 2016). 
For tree shadow detection, the minimum number of pixels for a tree shadow was set to 100. From the original images in Fig. 11a, results of intensity images and histogram thresholding are shown in Fig. 10b and 10d, leading to the global shadow masks shown in Fig. 11c, and finally to the tree label shadow masks in Fig. 11d. Usually urban scenes contain a high percentage of shadows, which makes easier the thresholding on the intensity image based on a bimodal histogram. However, dark materials in sunlit regions and bright materials in shaded regions may be falsely detected as shadows (Adeline et al., 2013a). To address these problems, the thresholding method of Nagao (1979) is used to remove water bodies (canal detected in U3 without shadow detection: Fig. 11c) and the morphological closing filter homogenizes shaded regions (white road lines and cars, U3: Fig. 11c). In the tree label shadow masks, the method visually performs well for trees in rows and less for clustered trees such as observed before. In some cases, the tree shadow is truncated or under-detected due to a local less accurate DSM horizontal and vertical description (tree in row at bottom-left in U3 and the clustered tree at middle-left in U1: Fig. 11d).
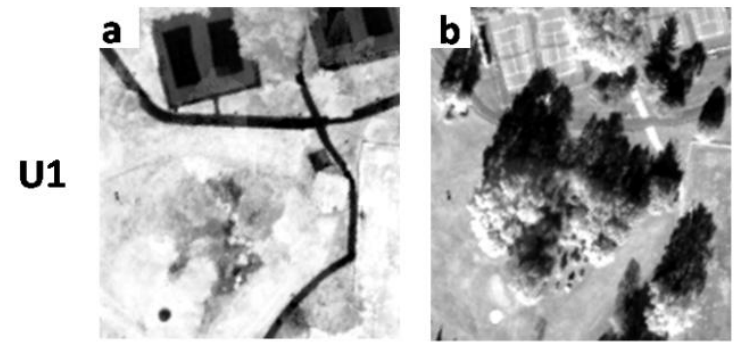

U3
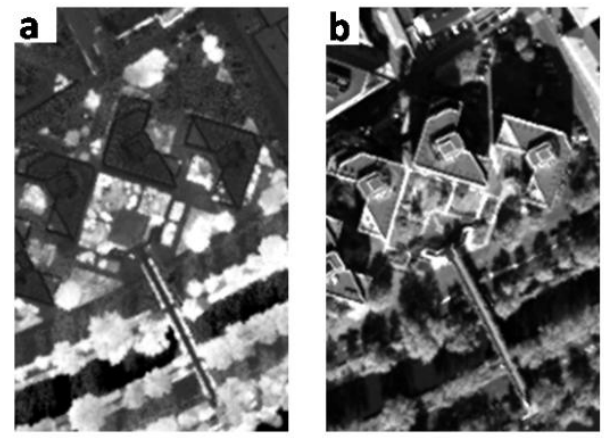

U2
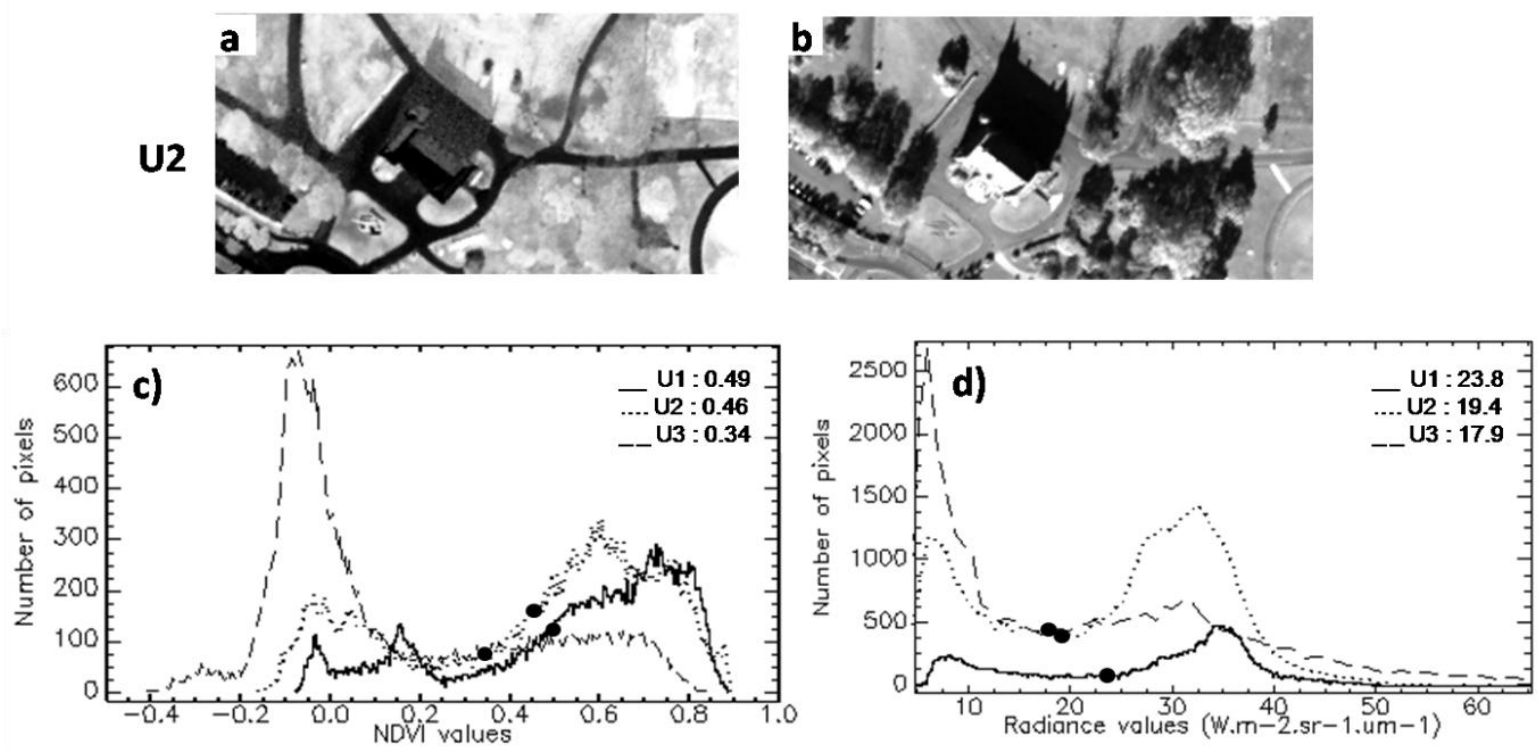
Fig. 10.a) NDVI images, b) intensity images, c) NDVI histograms and d) intensity histograms (black dots indicates thresholds values).

U1
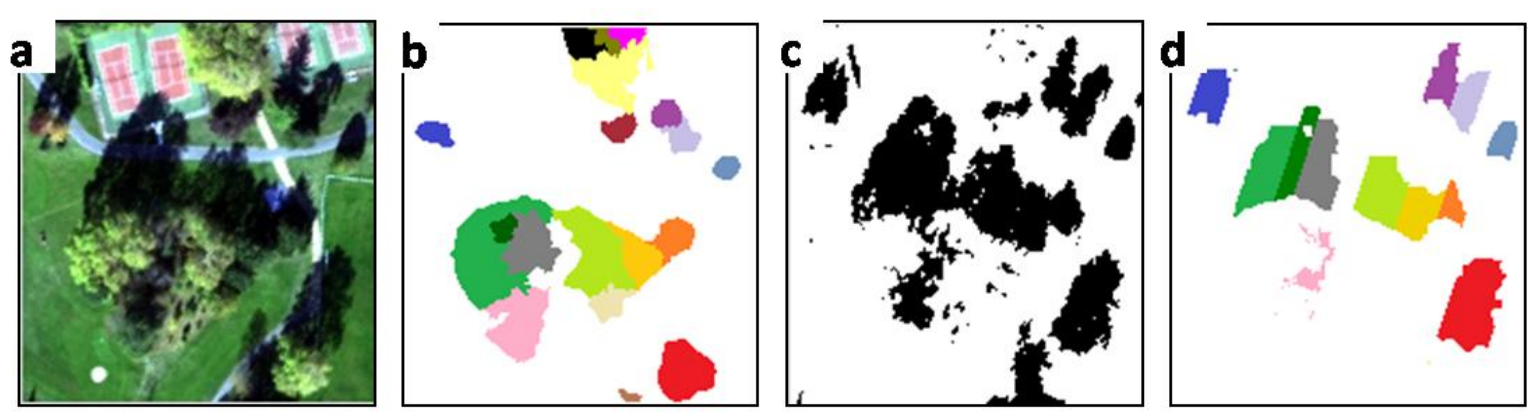

U2
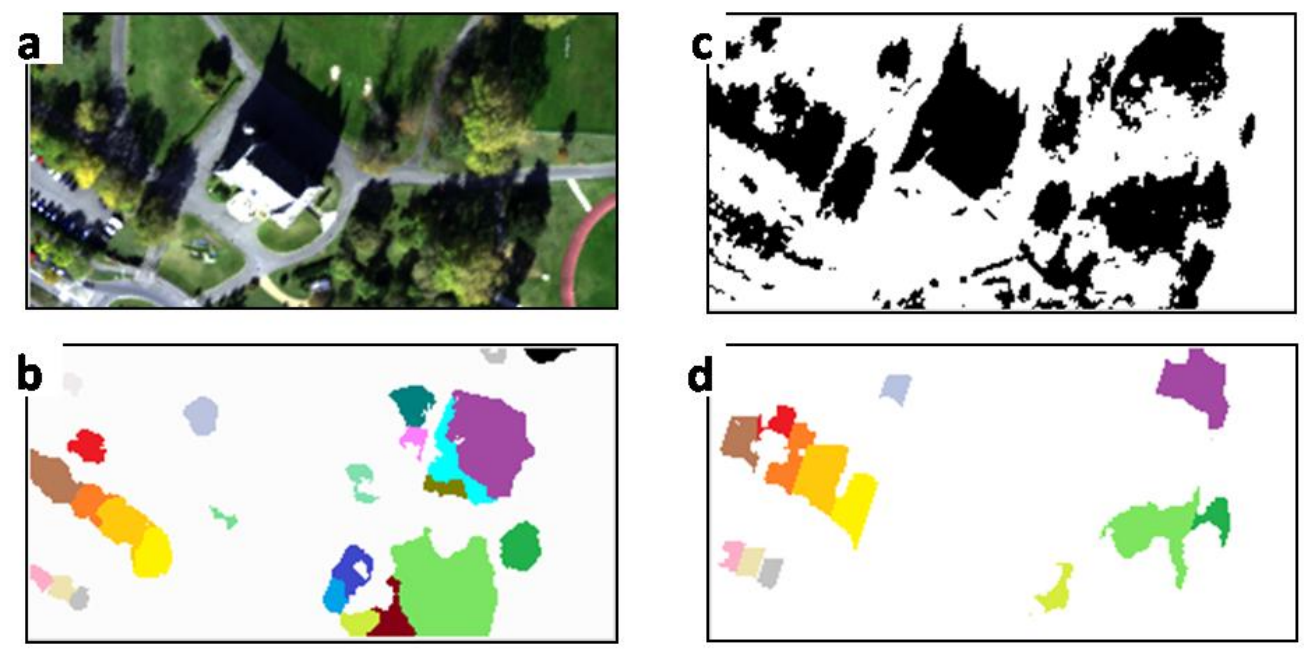

U3
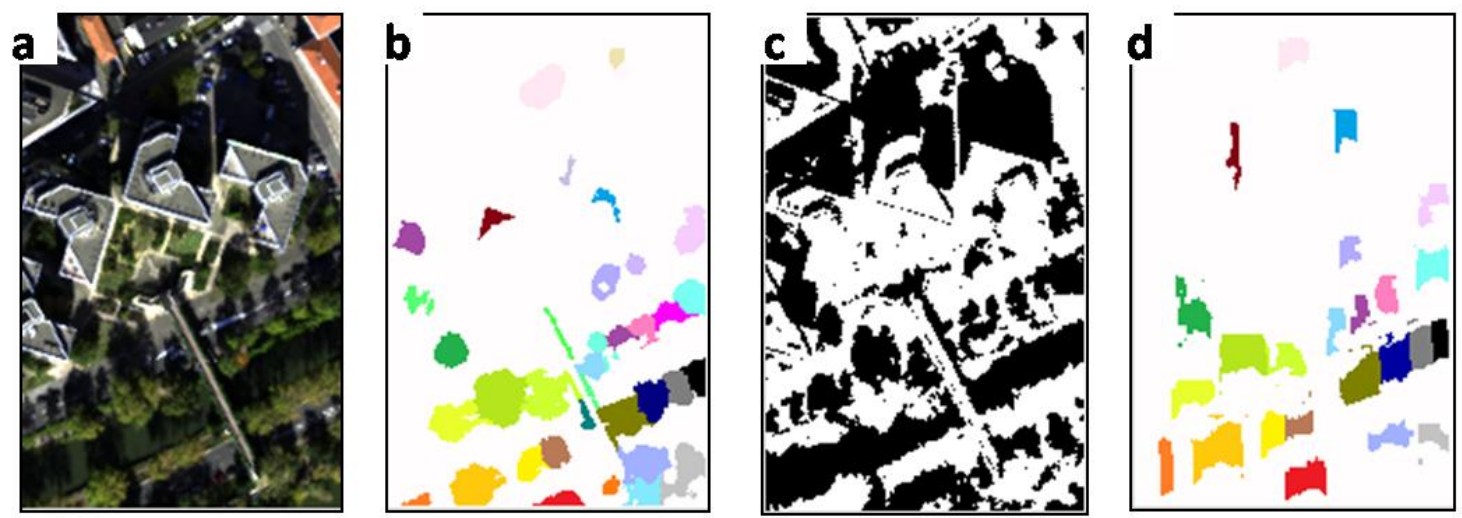

Fig. 11. a) RGB composite images, b) tree label masks, c) global shadow masks before applying the morphological filter and d) tree shadow label masks. 
LAI and tree viewing solid angle estimation (sections 3.4.1.2 and 3.4.2, cf. Fig. 2) are the last steps required to compute the final physics-based correction factor $\beta$ of ICARE-VEG.

For LAI estimation, the application of the LAI-NDVI regression model to the images shows the diversity of low estimated LAI values during the start of the fall season (Fig. 12). Without ground truth measurements, no validation can be performed. But on visual examination and by knowledge about the study site, qualitative comparison from one LAI to another seems correct if LAI values are not extreme (LAI close to 0 or superior to 4). Their values range is $0.77-2.35 \mathrm{~m}^{2} . \mathrm{m}^{-2}$ for $\mathrm{U} 1,0.63-2.06 \mathrm{~m}^{2} . \mathrm{m}^{-2}$ for $\mathrm{U} 2$ and $0.61-2.21 \mathrm{~m}^{2} \cdot \mathrm{m}^{-2}$ for $\mathrm{U} 3$. Improvements can be investigated in the future by adding the contribution of textural indices or geostatistical information in cases of heterogeneous and patchy spectral information over tree crowns (Colombo et al., 2003).

Finally for tree viewing solid angle estimation, $\Omega$ is computed for every pixel in each tree shadow. Its mean value is $0.16 \mathrm{sr}$ for $\mathrm{U} 1$ and $\mathrm{U} 2$, and $0.18 \mathrm{sr}$ for U3 (Fig. 12). For instance for the long cast shadow at the bottom right in U1, $\Omega$ values range between $2.0 \mathrm{sr}$ for the pixel the closest to the trunk and 0.36 sr for the pixel the furthest to the trunk.

U1
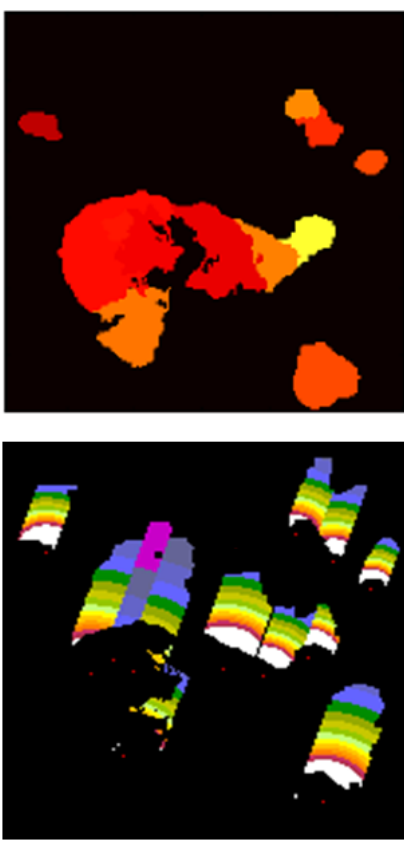

U2
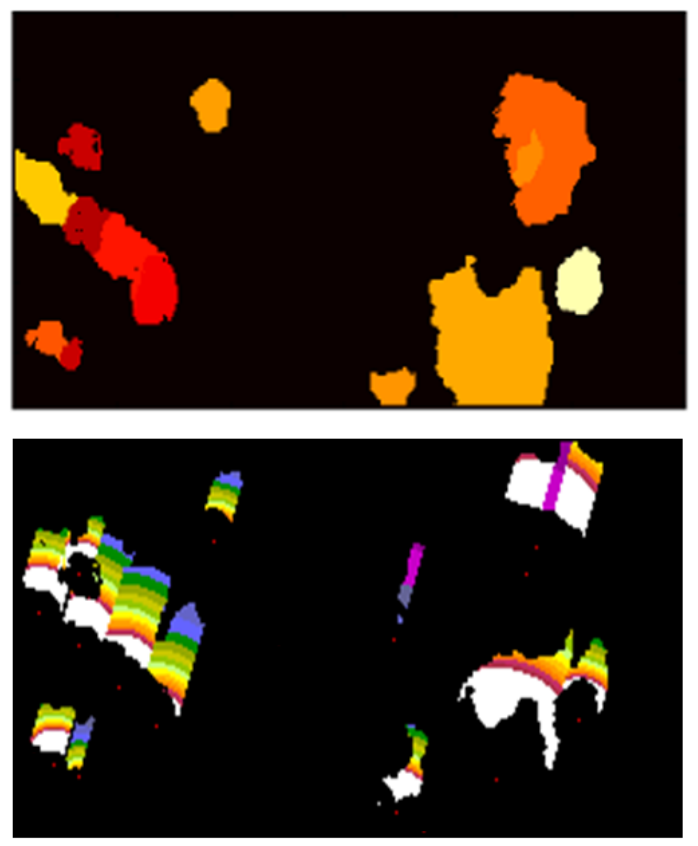

U3
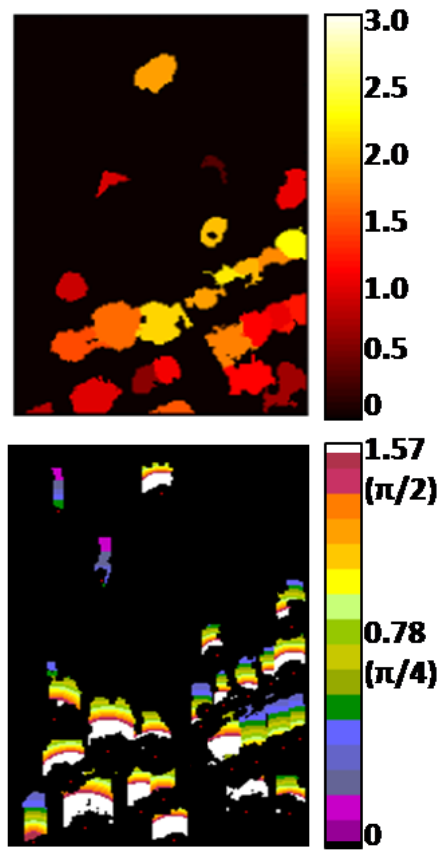

Fig. 12. LAI estimated from the LAI-NDVI regression model (first row) and tree viewing solid angles $\Omega$ computed in each tree shadow (second row; treetops are indicated in red dots).

\subsection{Spectral analysis and comparison between ICARE and ICARE-VEG}


The improvement of ICARE-VEG over ICARE in tree shaded regions is analyzed for 3 types of materials, namely grass (high variable reflectance), asphalt (intermediate flat reflectance), and water (very low reflectance), respectively for 2 trees with different LAI values (Fig. 13). Performances are assessed with the computation of the metrics, MAE and SAM (Eq. 12, Table 2), and by observing the spectral variability in the retrieved reflectance (Fig. 14). The results show that:

(i) the mean reflectance of ICARE in the tree shade is always overestimated compared to its counterpart in the sun. This is strengthened if the material in the shade has a high reflectance (i.e. grass compared to asphalt) and if the LAI is small (since the tree crown transmittance increases; Fig. 13). The MAE for ICARE in the tree shade is at least 4 times higher than the one with ICARE in the sun when compared to the ground truth (Table 2),

(ii) ICARE retrieved reflectance in the tree shade is distorted from visible to NIR bands, with a spectral increase starting at the red-edge position (particularly more visible for grass). This observation is in line with the previous comments on $\beta_{\text {ref }}$ (Fig. 12). ICARE-VEG correction attenuates this spectral distortion: SAM values are better by a multiplicative factor between 1.0 and 1.4 compared to ICARE (Table 2),

(iii) ICARE-VEG retrieves lower reflectance values than ICARE, and have a better accuracy due to the correction brought by $I_{\text {trans }}$ : its MAE decreases by a multiplicative factor between 2 and 4.5 when considering ground truth as a reference, and by a multiplicative factor between 4.2 and 18.8 when considering ICARE in the sun as a reference (Table 2). ICARE-VEG correction is spectrally-dependent; it is less notable in the visible range but becomes important in the NIR where ICARE can achieve non physical reflectance values higher than 1 (e.g. grass; Fig. 13a and 13b),

(iv) The spectral dispersion in ICARE retrieved reflectances increases from sunlit to shaded regions (Fig. 14). This may be due to penumbra and tree clumping effects impacting the spatial homogeneity of the tree shadow at ground. Globally, ICARE-VEG correction reduces this dispersion but not at the same order of magnitude of what ICARE in the sun does,

(v) The correction applied to water is the most challenging because of its very low reflectance, smaller than the $4 \%$ threshold in MAE selected as the desired accuracy for atmospheric correction models (Fig. 13). However, ICARE-VEG correction is promising 
since the order of magnitude in retrieved reflectances is correct as well as its global spectral shape,

(iv) The spectral differences between ICARE-VEG results and ground truth may be explained by the fact that ground truth has been measured close to tree shadow but in the sunny part, which induces spectral intra-class variability issue, and $\beta_{\text {ref }}$ factor brings a mean correction over the tree shadow, which cannot account for all local variations in tree shadow, especially when LAI is low.

At last, ICARE and ICARE-VEG are compared for all pixels belonging to the tree shadow label mask (U1: 5048 pixels, U2: 3843 pixels, U3: 4034 pixels). In the NIR band at $800 \mathrm{~nm}$, the decrease in the mean ICARE-VEG retrieved reflectance compared to ICARE is $43.3 \%$ for $\mathrm{U} 1,54.5 \%$ for $\mathrm{U} 2$ and $36.7 \%$ for $\mathrm{U} 3$. In the red band at $670 \mathrm{~nm}$, this decrease is $36.4 \%$ for $\mathrm{U} 1,51.8 \%$ for $\mathrm{U} 2$ and $40.1 \%$ for U3. At $800 \mathrm{~nm}$, ICARE reflectance is larger than 1 for $5.9 \%, 3.6 \%$ and $0.3 \%$ of pixels for $\mathrm{U} 1, \mathrm{U} 2$ and $\mathrm{U} 3$, respectively. ICARE-VEG reduces this percentage of pixels to $4.1 \%, 2.9 \%$ and $0.1 \%$, respectively.
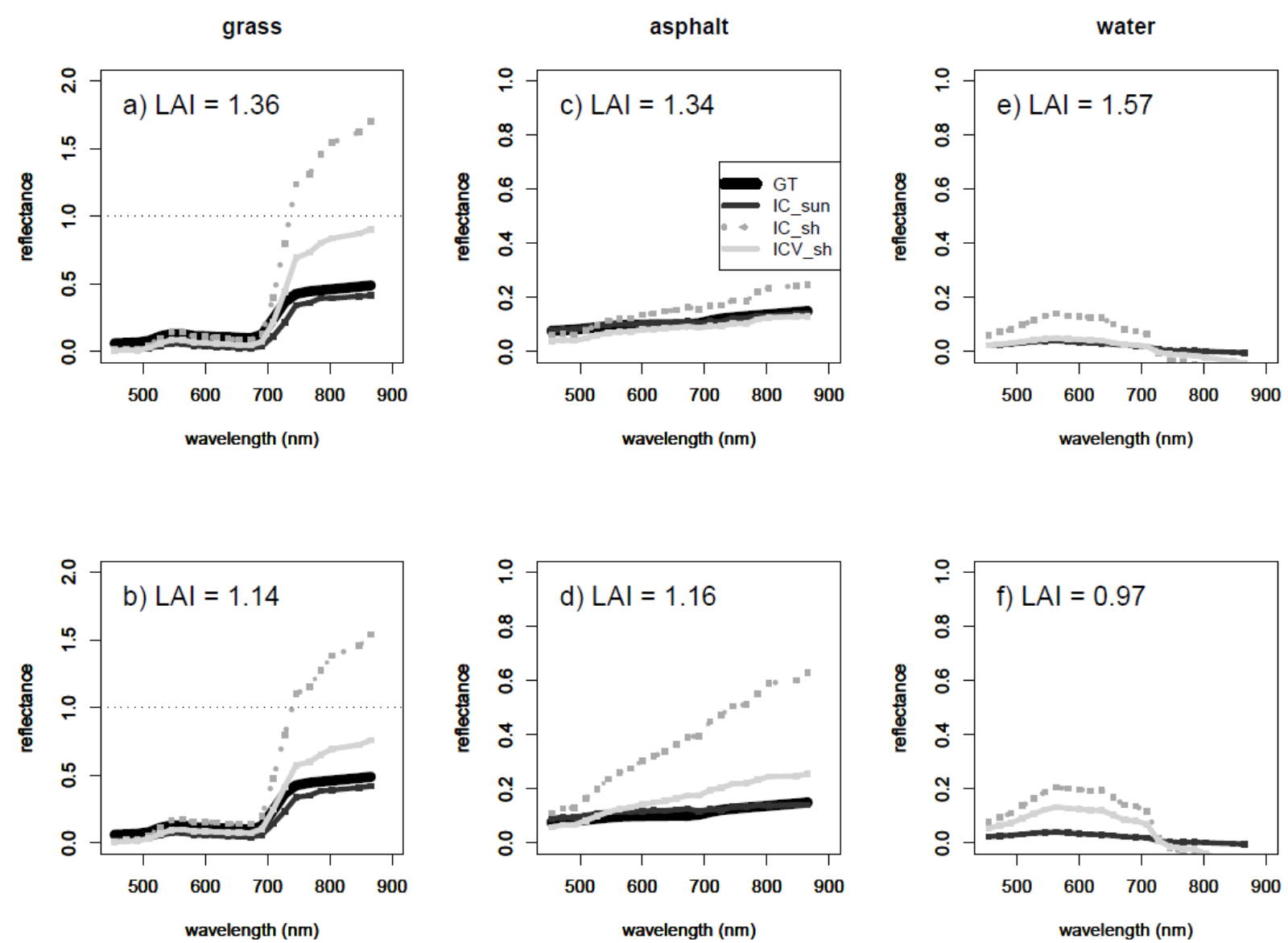

Fig. 13. ICARE reflectances in the sun ("IC_sun") and both ICARE and ICARE-VEG reflectances in the shade ("IC_sh" and "ICV_sh") for 3 ground materials (grass: first column, 
asphalt: second column, and water: third column) and for 2 different LAI values (high: first row and low: second row). In-situ measurements are also shown when available ("GT" : Ground Truth).

Table 2. ICARE and ICARE-VEG performance (MAE : Mean Absolute Error expressed in percentage of reflectance unit, and SAM : Spectral Angle Mapper expressed in radian unit) for scenarios from a to $\mathrm{f}$ (please refer to Fig. 13). Reference reflectance is in-situ measurements or ICARE in the sun. Bold numbers indicate MAE values lower than 4\%; "_" stands for unavailable data.

\begin{tabular}{ccccccccc}
\hline Reference & Test & Metrics & a) & b) & c) & d) & e) & f) \\
\hline \multirow{4}{*}{ In-situ } & ICARE (sun) & MAE & $7.6 \%$ & $6.5 \%$ & $\mathbf{0 . 5 \%}$ & $\mathbf{1 . 3 \%}$ & & \\
& & SAM & 0.22 & 0.15 & 0.05 & 0.09 & - & - \\
ICARE & MAE & $31.7 \%$ & $29.0 \%$ & $4.6 \%$ & $25.2 \%$ & & \\
(sun) & (shadow) & SAM & 0.26 & 0.21 & 0.17 & 0.23 & - & - \\
& & & 13.1 & & & & & \\
& ICARE-VEG & MAE & $\%$ & $8.2 \%$ & $\mathbf{2 . 3 \%}$ & $5.7 \%$ & & \\
& (shadow) & SAM & 0.25 & 0.19 & 0.13 & 0.18 & - & - \\
ICARE & ICARE & MAE & $37.1 \%$ & $34.2 \%$ & $4.7 \%$ & $24.0 \%$ & $10.6 \%$ & $7.1 \%$ \\
(sun) & (shadow) & SAM & 0.07 & 0.07 & 0.20 & 0.30 & 0.37 & 0.49 \\
& ICARE-VEG & MAE & $14.2 \%$ & $10.5 \%$ & $\mathbf{2 . 3 \%}$ & $5.1 \%$ & $6.0 \%$ & $\mathbf{1 . 1 \%}$ \\
& (shadow) & SAM & 0.05 & 0.05 & 0.15 & 0.25 & 0.34 & 0.42 \\
\hline
\end{tabular}


grass
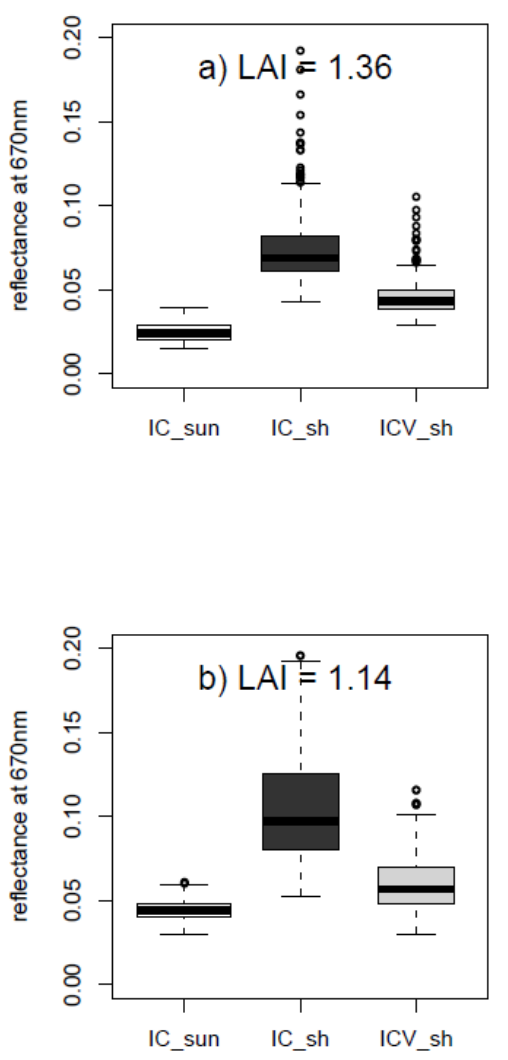

670

30

31

32

33

34

35

36

37

38

39

40

41

42

43

44

45

46

47

48

49

50

51

52

53

54

55

56

57

58

59671

60

61

62
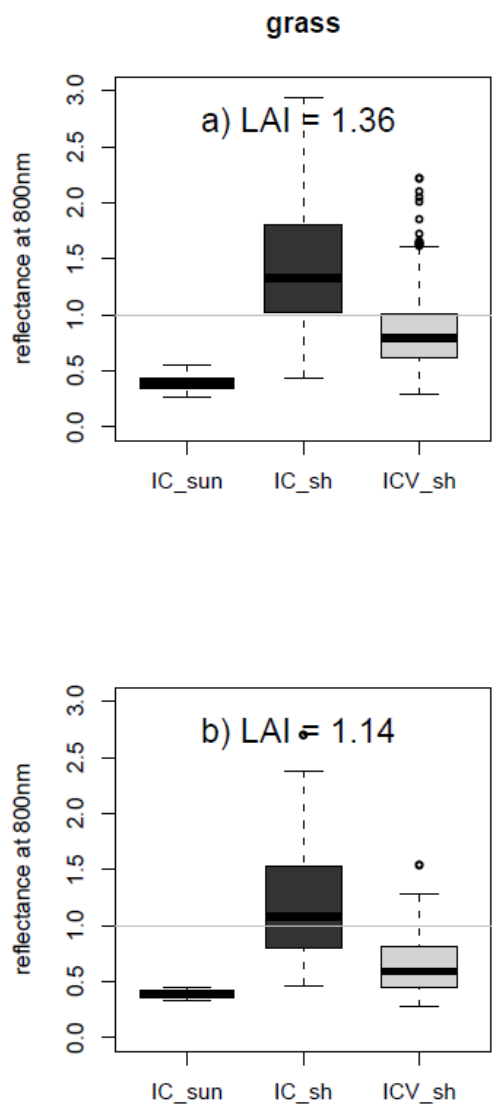

asphalt
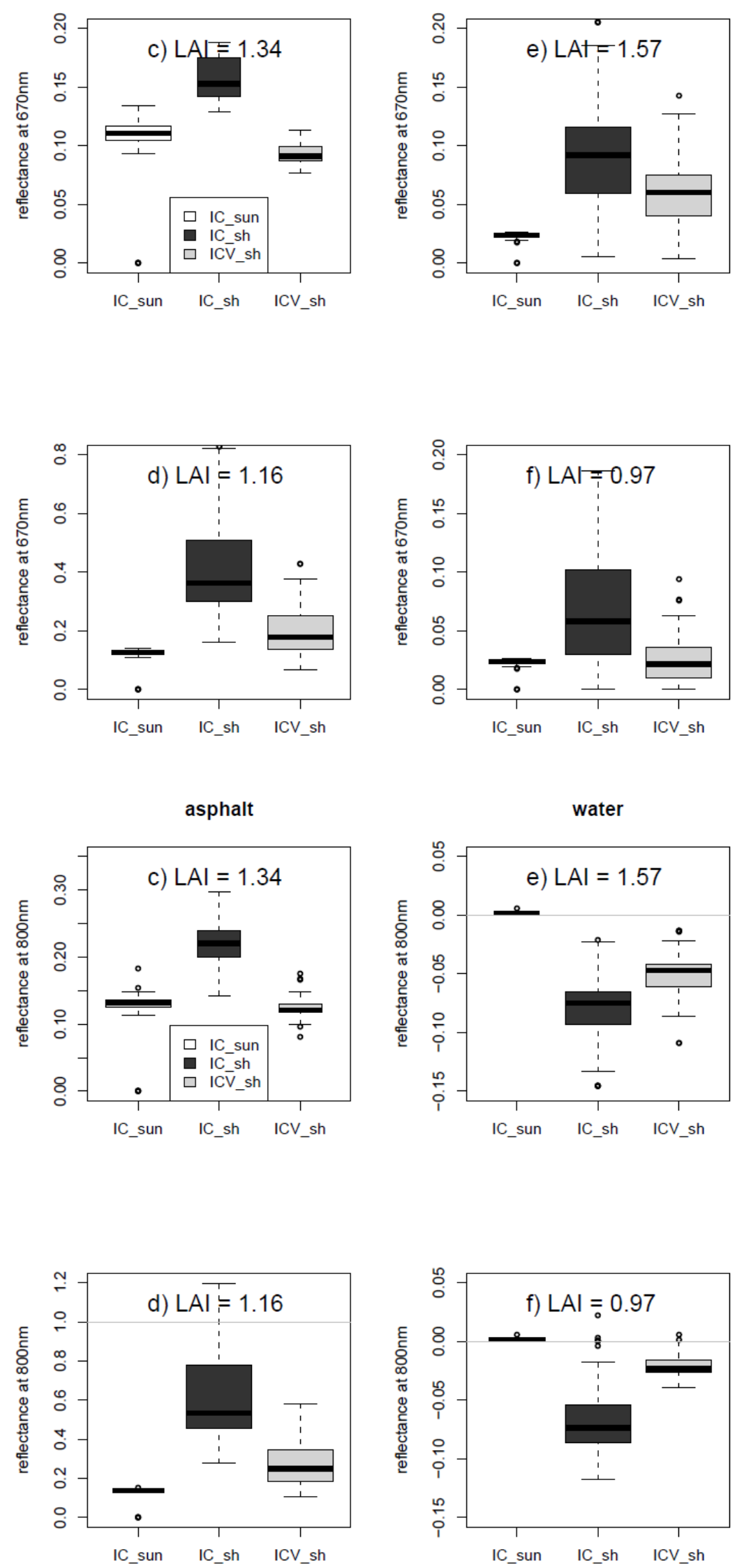
Fig. 14. Reflectance variability in red band (2 first rows) and NIR band (2 last rows) for ICARE in the sun ("IC_sun") and both ICARE and ICARE-VEG in the shade ("IC_sh" and "ICV_sh" respectively) for scenarios from a to f (please refer to Fig. 13).

\section{Conclusions}

ICARE-VEG improves ICARE 3D atmospheric correction in order to correct retrieved surface reflectances in presence of tree shadows. It includes image-based techniques such as tree crown delineation and tree shadow detection, and then the application of a spectral and geometrical physics-based correction factor in tree shadow pixels following each tree crown characteristics. Since this issue is relatively new, the strategy was based on a complex exploratory methodology by using the DART 3D canopy radiative transfer model, and heads towards the development of a semi-automatic method. ICARE-VEG only considers deciduous trees with green healthy leaves and surfaces with a lambertian spectral behaviour.

The application of ICARE-VEG on VNIR hyperspectral high spatial resolution data and the comparison between ICARE and ICARE-VEG clearly stress that a large inaccuracy occurs if tree crown transmission is neglected. Globally, results were encouraging and showed that (i) neglecting the transmitted irradiance demonstrates an over-estimation in retrieved reflectances, the higher the material reflectance is and the lower the tree LAI is, (ii) this bias increases from visible to NIR at the red-edge position, which is due to the additive contribution of the diffuse over the direct transmitted irradiance in the total transmitted irradiance received at tree shadow; ICARE-VEG attenuated this spectral distortion by a multiplicative factor between 1.0 and 1.4 by means of spectral angle mapper performance, (iii) ICARE-VEG improves the mean absolute error in retrieved reflectances compared to ICARE in tree shadows by a multiplicative factor ranging between 4.2 and 18.8 for some test cases (taking ICARE in the sun as reference), and (iv) for a given wavelength, the spectral variability in the retrieved reflectances increases from sunlit to shaded regions due to penumbra and tree clumping effects, which makes difficult for the ICARE-VEG correction to exactly reduce at the same order of magnitude of what ICARE does in sunlit regions.

These results highlight the complexity to model physical natural processes with finer spatial resolutions. The difficulty relies on the high number of sources of variability to cope with, among them, the spectral and spatial dimensions for the tree shadow correction, the intra-class variability for a given material, and the intrinsic characteristics of urban areas (Small, 2001). 
Future work includes the validation of ICARE-VEG in the Short Wave Infrared Region (SWIR: 1.0-2.5 $\mu \mathrm{m}$ ), the replacement of $6 \mathrm{SV}$ atmospheric code with MODTRAN (MODerate resolution atmospheric TRANsmission; Berk et al, 1999) in ICARE-HS, and the comparison of 3D atmospheric codes in urban areas between the fusion of ICARE-VEG and ICARE-HS and ATCOR-4. Moreover, a better analysis of the direct and diffuse transmitted irradiance terms in presence of a tree crown is planned to better understand the possible sources of errors and improvements of ICARE-VEG.

\section{Acknowledgements}

This work was funded by ONERA and the French Research Agency in the framework of the ANR VegDUD proposal studying the role of vegetation in sustainable urban development. We would like to thank the CESBIO DART team (Nicolas Lauret, Tristan Gregoire, JéromeCros) for their useful advices and server resources as well as the ONERA IT department, Benedicte Diez and Sidonie Levebvre (ONERA) and Fabrice Vinatier (LISAH) for their support about the use of ICARE and statistical issues.

\section{Appendix A}

To assess the most influent variables $X^{\prime}$, a global sensitivity analysis based on ANOVA is applied on a second degree polynomial expression with first order interactions between the inputs $X=\{$ LAI, ALA, POROSITY, LOP, GROUND, SUN, VISI $\}$ and the output $\beta_{\text {ref }}$. For each spectral band, the regression fit between $X$ and $\beta_{\text {ref }}$ gives: $\mathrm{R}^{2}>0.98$ and $\mathrm{p}-$ value $<1 \%$. The sensitivity index $\eta^{2}$ is computed for 4 ranges of LAI from the results of ANOVA: full LAI range (0.5-8), low LAI (0.5-2), medium LAI (2-3.5) and high LAI (3.5-8). Results are shown in Table A.1.

Table A.1. Median values of the sensitivity index $\eta^{2}$, expressed in total percentage accounting for the contribution of the variable in the variance of $\beta_{\text {ref }}$ computed over the spectral domain for different LAI ranges and based on ANOVA results. Each single variable represents its main effect (coefficient of the variable taken alone and squared except for the qualitative variables: LOP, GROUND, VISI); the interaction effect is the sum of all combinations 
between the variables; residuals stand for the missing contribution from other variables or errors in the fitting regression model of $\beta_{\text {ref }}$.

\begin{tabular}{l|c|ccc}
\cline { 2 - 5 } & \multicolumn{4}{c}{ LAI range } \\
\hline Variables (Df) & $\begin{array}{c}0.5 \leq \mathrm{LAI} \leq 8 \\
(\mathrm{n}=3490)\end{array}$ & $\begin{array}{c}0.5 \leq \mathrm{LAI} \leq 2 \\
(\mathrm{n}=1296)\end{array}$ & $\begin{array}{c}2 \leq \mathrm{LAI} \leq 3.5 \\
(\mathrm{n}=1296)\end{array}$ & $\begin{array}{c}3.5 \leq \mathrm{LAI} \leq 8 \\
(\mathrm{n}=1296)\end{array}$ \\
\hline LAI (2) & $\mathbf{7 2 . 1}$ & $\mathbf{4 1 . 6}$ & $\mathbf{2 4 . 1}$ & $\mathbf{1 5 . 2}$ \\
ALA (2) & 1.5 & 1.1 & 5.4 & 8.5 \\
POROSITY (2) & 0.9 & 0.2 & 2.3 & 8.3 \\
LOP (2) & 0.0 & 0.0 & 0.0 & 0.0 \\
GROUND (1) & 0.0 & 0.0 & 0.0 & 0.0 \\
SUN (2) & $\mathbf{1 8 . 2}$ & $\mathbf{3 8 . 1}$ & $\mathbf{5 1 . 2}$ & $\mathbf{5 0 . 2}$ \\
VISI (1) & 3.6 & 13.8 & 9.1 & 6.2 \\
Interactions (27) & 2.6 & 3.2 & 7.1 & 10.0 \\
Residuals & 1.1 & 2.0 & 0.8 & 1.6 \\
\hline
\end{tabular}

${ }^{a}$ Degree of Freedom

Whatever the LAI range, $\eta^{2}$ values showed few spectral dependence except locally on the red-edge with around 10\% maximum variation (data not shown). In one side for the full LAI range $(0.5 \leq \mathrm{LAI} \leq 8)$ and by order of importance, LAI and SUN contribute the most to $\beta_{\text {ref }}$ variance, then VISI, the interactions (mainly dominated by ALA with SUN), ALA, POROSITY, and at last no contribution for LOP and GROUND. These two last variables might interfere in the radiative budget (i.e. $\beta_{r e f}$ ) at a second level compared to LAI and SUN since the contribution of the direct light is predominant over the diffuse light within the canopy. On the other side, by considering LAI ranges, the more LAI increases, the more the influence of LAI and VISI is reduced for the increasing benefit of SUN, ALA, the interactions (e.g. ALA with SUN) and POROSITY. Indeed, increasing tree clumping and both sun zenith angle and leaf orientation gets more transparency in a very closed canopy (i.e. high LAI). Finally, LAI and SUN are selected as $X^{\prime}$ variables to estimate $\beta_{\text {ref }}$.

\section{Appendix B}

The solid angle viewing a surface situated in the upper space from any point is usually defined by: 
$\Omega=\int_{0}^{\pi / 2} \int_{\varphi_{\min }}^{\varphi_{\max }} \cos (\theta) \cdot d \varphi \cdot d \theta=\int_{0}^{\pi / 2} \Delta \varphi(\theta) \cdot \cos (\theta) d \theta$

$\theta$ denotes the elevation angle (which is not the standard notation in spherical coordinate system), and $\varphi$ the azimuth angle (anticlockwise from South direction, e.g. X axis). $\Delta \varphi(\theta)=\varphi_{\max }(\theta)-\varphi_{\min }(\theta)$ is the partial angle of the object for a given $\theta$ and is set to 0 when the object is out of reach for a given direction $(\theta, \varphi)$. However, here the tree crown is assumed to have an ellipsoid shape (Essery et al., 2008; Fig. 5), hence $\Delta \varphi(\theta)$ expression is not trivial to determine and to integrate since it depends on $\theta$ variations.

Let's consider a given point $C(0,0,0)$ situated in the tree shadow. $C$ is the centre of the Cartesian coordinates system. The coordinates of the base of the trunk $T$ are $\left(\mathrm{x}_{0}, \mathrm{y}_{0}, 0\right)$, the total tree height is $H_{\text {tree }}$, the trunk height $H_{\text {trunk }}=H_{\text {tree }} / 4$, the tree crown has a diameter of $D_{\text {tree }}$ and is modelled by an ellipsoid with a revolution symmetry in $\mathrm{Z}$ axis:

$\frac{\left(x-x_{0}\right)^{2}+\left(y-y_{0}\right)^{2}}{r_{h}^{2}}+\frac{\left(z-z_{0}\right)^{2}}{r_{v}^{2}}=1$

with $r_{h}=D_{\text {tree }} / 2$ denotes the horizontal tree radius of the crown diameter, $r_{v}=\left(H_{\text {tree }}-\right.$ $\left.H_{\text {trunk }}\right) / 2$ is the vertical radius, and $z_{0}=H_{\text {trunk }}+H_{\text {tree }} / 2$ is the altitude of the ellipsoid centre. For any ray beam emitted from point $\mathrm{C}(0,0,0)$ in a given direction denoted by the couple of angles $(\theta, \varphi)$, the parametric equation is:

$C(l)=\left(\begin{array}{c}l \cdot \cos (\theta) \cdot \cos (\varphi) \\ l \cdot \cos (\theta) \cdot \sin (\varphi) \\ l \cdot \sin (\theta)\end{array}\right)$

$$
\left\{\begin{array}{c}
a=\frac{\cos ^{2}(\theta)}{r_{h}^{2}}+\frac{\sin ^{2}(\theta)}{r_{v}^{2}} \\
b=\frac{-2 \cdot \cos (\theta) \cdot\left(x_{0} \cdot \cos (\varphi)+y_{0} \cdot \sin (\varphi)\right)}{r_{h}^{2}}-\frac{2 \cdot \sin (\theta) \cdot z_{0}}{r_{v}^{2}} \\
c=\frac{\mathrm{x}_{0}^{2}+\mathrm{y}_{0}^{2}}{r_{h}^{2}}+\frac{\mathrm{z}_{0}^{2}}{r_{v}^{2}}-1
\end{array}\right.
$$


$\varphi_{0}$ is defined as the azimuth of point $T$. The expression of parameter $b$ can be rewritten as follows:

$b=F_{2}[\theta] \cdot \cos \left(\varphi-\varphi_{0}\right)+F_{3}[\theta]$ with $\left\{\begin{array}{c}F_{2}[\theta]=-\frac{2 \cdot \cos (\theta) \cdot \sqrt{x_{0}^{2}+y_{0}^{2}}}{r_{h}^{2}} \\ F_{3}[\theta]=-\frac{2 \cdot \sin (\theta) \cdot z_{0}}{r_{v}^{2}}\end{array}\right.$

In order to find only one solution to this quadratic equation, i.e. when the ray intersects the tree crown surface at only one point located at the borders of the tree crown, the equality $b^{2}-4 a c=0$ must comply with:

$$
b=2 \sqrt{a c}=F_{1}[\theta]=2 \sqrt{\left(\frac{\cos ^{2}(\theta)}{r_{h}^{2}}+\frac{\sin ^{2}(\theta)}{r_{v}^{2}}\right)\left(\frac{\mathrm{x}_{0}^{2}+\mathrm{y}_{0}^{2}}{r_{h}^{2}}+\frac{\mathrm{z}_{0}^{2}}{r_{v}^{2}}-1\right)}
$$

Thus, two solutions are resulting for $\varphi$ :

$$
\varphi=\varphi_{0} \pm \Delta \varphi / 2 \operatorname{with} \Delta \varphi=2 \arccos \left(\frac{F_{1}[\theta]-F_{3}[\theta]}{F_{2}[\theta]}\right)
$$

Since the azimuth of the two borders are symmetric, $\Delta \varphi$ is centred on the azimuth of the trunk (i.e. $\varphi_{0}$ ). By reporting Eq. B.6 and Eq. B.5 in Eq. B.1, the integration will be solved numerically by using the Riemann integral, further validated with a Monte Carlo method. $\Delta \varphi$ will be set to 0 when the tree is out of reach, i.e. for values of $\theta$ leading to $\left|\frac{F_{1}[\theta]-F_{3}[\theta]}{F_{2}[\theta]}\right|>1$, where the arcos function is not defined.

\section{REFERENCES}

Adeline, K.R.M., Chen, M., Briottet, X., Pang, S.K., Paparoditis, N., 2013a. Shadow detection in very high spatial resolution, aerial images: A comparative study. ISPRS Journal of Photogrammetry and Remote Sensing 80: 21-38.

814 Papelard, J.-P., Déliot, P., Duffaut, J., Airault, S., David, N., Maillet, G., Poutier, L., Foucher, 815 P.-Y., Achard, V., Souchon, J.-P., Thom, C., 2013b.Description de la campagne aéroportée 816 UMBRA: étude de l'impact anthropique sur les écosystèmes urbains et naturels avec des 
images THR multispectrales et hyperspectrales. Revue française de photogrammétrie et de télédétection 202: 79-92.

Adeline, K., Briottet, X., Paparoditis, N., 2012. Material reflectance retrieval in shadow due to urban vegetation from 3D lidar data and hyperspectral airborne imagery.In 32nd EARSeL Symposium and 36th General Assembly, Advances in Geosciences, Mykonos, Greece.

AErosol RObotic NETwork - AERONET, NASA's Goddard Space Flight Centre, https://aeronet.gsfc.nasa.gov/.

Alonzo, M., Bookhagen, B., RobertsD., 2014.Urban tree species mapping using hyperspectral and lidar data fusion. Remote Sensing of Environment, 148:70-83.

Baret, F., Guyot, G., 1991.Potentials and limits of vegetation indices for lai and apar assessment. Remote Sensing of Environment, 35(2-3):161-173.

Berk, A., Anderson, G., Bernstein, L., Acharya, P., Dothe, H., Matthew, M., AdlerGolden, S., Chetwynd Jr., J., Richtsmeier, S., Pukall, B., Allred, C., Jeong, L., Hoke, M., 1999. MODTRAN4 radiative transfer modeling for atmospheric correction. In Proceedings SPIE Annual Meeting 3756, Denver, CO, pp. 348-353.

Burnham, K., Anderson, D. R., 2004. Multimodel inference understanding aic and bic in model selection. Sociological Methods \& Research, 33(2):261-304.

Campbell, G., 1990.Derivation of an angle density function for canopies with ellipsoidal leaf angle distributions. Agricultural and Forest Meteorology, 49(3): 173-176.

Ceamanos, X., Briottet, X., Roussel, G., GilardyH., Adeline, K., 2017.Using 3D information for atmospheric correction of airborne hyperspectral images of urban areas.2017 Joint Urban Remote Sensing Event (JURSE), Dubai, pp. 1-4.

Chen, M., Seow, K. L. C., Briottet, X., Pang, S. K., 2013. Efficient empirical reflectance retrieval in urban environments. IEEE Journal of Selected Topics in Applied Earth Observations and Remote Sensing, 6(3) : 1596-1601. 
Colombo, R., Bellingeri, D., Fasolini, D., Marino, C. M., 2003. Retrieval of leaf area index in different vegetation types using high resolution satellite data. Remote Sensing of Environment, 86(1): 120-131.

Combal, B., Baret, F., Weiss, M., Trubuil, A., Mace, D., Pragnere, A., Myneni, R., Knyazikhin, Y., Wang, L., 2002.Retrieval of canopy biophysical variables from bidirectional reflectance - using prior information to solve the ill-posed inverse problem. Remote Sensing of Environment, 84(1):1-15.

Damm, A., Guanter, L., Verhoef, W., Schläpfer, D., Garbari,S., Schaepman, M.E., 2015.Impact of varying irradiance on vegetation indices and chlorophyll fluorescence derived from spectroscopy data, Remote Sensing of Environment, 156 : 202-215.

Dare,P., 2005. Shadow analysis in high-resolution satellite imagery of urban areas. Photogrammetric Engineering and Remote Sensing, 71:169-177.

Dell'Acqua, F., Gamba, P., Lisini, G., 2005.Urban land cover mapping using hyperspectral and multispectral vhr sensors: spatial versus spectral resolution. In Proc. URBAN, IAPRS, volume XXXVI-8/W27, Tempe, AZ, USA.

Droesbeke, J.-J., Saporta, G., Fine, J., and Société de statistique Association pour la statistique et ses utilisations en France. Plans d'expériences: applications à l'entreprise. Editions TECHNIP.

Duffaut, J. and Déliot P., 2005. Characterization and calibrationof a high-resolution multispectral airborne digital camera.Optical Complex Systems, Marseille (France), October 24, 2005.

Essery, R., Bunting, P., Rowlands, A., Rutter, N., Hardy,J., Melloh, R., Link, T., Marks, D., Pomeroy, J., 2008.Radiative transfer modeling of a coniferous canopy characterized by airborne remote sensing. J. Hydrometeor, 9: 228-241. 
Gamon, J., Penuelas, J., Field, C., 1992. A narrow-waveband spectral index that tracks diurnal changes in photosynthetic efficiency. Remote Sensing of environment, 41: 35-44.

Gastellu-Etchegorry, J.-P., Demarez, V., Pinel, V., Zagolski, F., 1996.Modeling radiative transfer in heterogeneous 3-d vegetation canopies. Remote Sensing of Environment, 58(2): $131-156$.

Iovan, C., Cournede, P.-H.,Guyard, T.,Bayol, B.,Boldo, D., Cord, M., 2014. Model-Based Analysis-Synthesis for Realistic Tree Reconstruction and Growth Simulation. Geoscience and Remote Sensing, IEEE Transactions on, 52(2): 1438-1450.

Jacquemoud, S., Bidel, L., François, C., Pavan, G., 2003. ANGERS leaf optical properties database, Angers, France, June 2003, http://opticleaf.ipgp.fr/index.php?page=database.

Jensen, J.,Cowen, D., 1999. Remote sensing of urban/suburban infrastructure and socioeconomic attributes. Photogrammetric Engineering and Remote Sensing, 65:611-622.

Jensen, R. R., Hardin, P. J., Hardin, A. J., 2012. Estimating Urban Leaf Area Index (LAI) of Individual Trees with Hyperspectral Data. Photogrammetric Engineering \& Remote Sensing, 5(10): $495-504$.

Kruse, F. A., Lefkoff, A. B., Boardman, J.W., Heidebrecht, K.B., Shapiro, A.T., Barloon, P.J., Goetz, A.F.H., 1993. The Spectral Image Processing System (SIPS) - Interactive visualization and analysis of Imaging Spectrometer data. Remote Sensing of Environment 44: 145 - 163.

Lachérade, C.,Miesch, D.,Boldo, X.,Briottet, C.,Valorge, Le Men, H., 2008.Icare: A physically-based model to correct atmospheric and geometric effects from high spatial and spectral remote sensing images over 3d urban areas. Meteorology and Atmospheric Physics, 102(3-4):209-222.

Liow, Y., Pavlidis, T., 1990.Use of shadows for extracting buildings in aerial images.Computer Vision, Graphics, and Image Processing 49 (2) : 242-277.

Monod, H., Naud, C., Makowski, D., 2006. Working with Dynamic Crop Models - Chapter 3 
918 Uncertainty and sensitivity analysis for crop models.Edited by Daniel Wallach, David

Makowski and James W. Jones, Elsevier B.V.

Nagao, M., Matsuyama, T., Ikeda, Y., 1979. Region extraction and shape analysis in aerial photographs. Computer Graphics and Image Processing, 10(3):195-223.

Norman,J., Welles, J., 1983. Radiative transfer in an array of canopies. Agronomy Journal, 75(3):481-488.

Olejnik, S., Algina, J., 2003. Generalized eta and omega squared statistics: measures of effect size for some commonresearch designs. Psychological Methods, 8(4):434-447.

Otsu, N., 1979. A threshold selection method from gray-level histograms. IEEE Transactions on Systems, Man and Cybernetics, 9(1):62-66.

Pierrot-Deseilligny, M., Paparoditis, N., 2006.A multiresolution and optimization-based image matching approach: An application to surface reconstruction from SPOT5-HRS stereo imagery. International Archives of the Photogrammetry, Remote Sensing and Spatial Information Sciences 36 (1/W41).

Puissant, A., Weber, C., 2014. Les images à très haute résolution spatiale: une source d'information géographique en milieu urbain ? état des lieux et perspectives. L'Espace Géographique, 4:345-356.

Rese ATCOR-4 User Guide, Version 7.0.3, March 2016, http: www.rese.ch/pdf/atcor4_manual.pdf

Richter, R., Schläpfer, D., 2002. Geo-atmospheric processing of airborne imaging spectrometry data.part 2: Atmospheric/topographic correction. International Journal of Remote Sensing, 23(13):2631-2649.

949 Roessner, S., Segl, K., Heiden, U., Kaufmann, H., 2001.Automated differentiation of urban 950 surfaces based on airborne hyperspectral imagery. Geoscience and Remote Sensing, IEEE Transactions on, 39(7) : 1525-1532. 
Rosenbaum, D., Leitloff, J., Kurz, F., Meynberg, O., Reize, T.,2010.Real-time image processing for road traffic data extraction from aerial images.volume Proceedings of ISPRS Technical Commission VII Symposium, XXXVII (7B), pages 469-474, Vienna, Austria.

Rosskopf, E., Morhart, C., Nahm, M., 2017. Modelling Shadow Using 3D Tree Models in High Spatial and Temporal Resolution. Remote Sensing, 9(7): 719.

Rouse,J., 1974. Monitoring the vernal advancement and retrogradation (green wave effect) of natural vegetation.Technical report, Progress Report RSC 1978-2 for NASA, Greenbelt, USA.

Sampson, D.A., Smith, F.W, 1993. Influence of canopy architecture on light penetration in lodgepole pine (Pinuscontorta var. latifolia) forests. In Agricultural and Forest Meteorology, 64(1-2): 63-79.

Schläpfer, D., Bojinski, S., Schaepman, M., Richter, R., 2000.Combination of geometric and atmospheric correction for AVIRIS data in rugged terrain.AVIRIS Workshop,Pasadena CA.

Schläpfer,D., Richter, R.,Damm, A., 2013. Correction Of Shadowing In Imaging Spectroscopy Data By Quantification Of The Proportion Of Diffuse Illumination. Presented at the 8th SIG-IS EARSeL Imaging Spectroscopy Workshop, Nantes, pp. 10.

Schläpfer, D., Richter R., Feingersh, T., 2015.Operational BRDF Effects Correction for Wide-Field-of-View Optical Scanners (BREFCOR). IEEE Transactions on Geoscience and Remote Sensing, vol. 53(4): 1855-1864.

Shahtahmassebi, A., Yang, N., Wang, K., Moore, N., Shen, Z., 2013. Review of Shadow Detection and De-Shadowing Methods in Remote Sensing.Chinese Geographical Science 23 (4): 403-420.

Small C.,2001.Spectral dimensionality and scale of urban radiance.Presented at 2001 AVIRIS 
985 Vermote, E.F., Tanré, D., Deuzé, J.L., Herman, M., Morcrette, J.-J., 1997.Second Simulation

1 of the Satellite Signal in the Solar Spectrum, 6S: An Overview, IEEE Transactions on Geoscience and Remote Sensing, 35(3): 675-686.

Weiss, M., Baret, F., Myneni, R. B., Pragnére, A., Knyazikhin, Y., 2000.Investigation of a model inversion techniqueto estimate canopy biophysical variables from spectral and directional reflectance data.Agronomie, 20(1):3-22.

Wulder, M.A., Hall, R.J., Coops, N.C., Franklin, S.E., 2004. High spatial resolution remotely sensed data for ecosystem characterization. BioScience 54: 511-521.

Yuan, F., Bauer, M.E., 2006. Mapping impervious surface area using high resolution imagery: A comparison of object-based and per pixel classification. In American Society for Photogrammetry and Remote Sensing Annual Conference Proceedings, Reno, Nevada, USA.

Zhen, Z., Quackenbush, L. J., Zhang, L, 2016. Trends in Automatic Individual Tree Crown Detection and Delineation—Evolution of LiDAR Data. Remote Sensing, 8(4):333. 


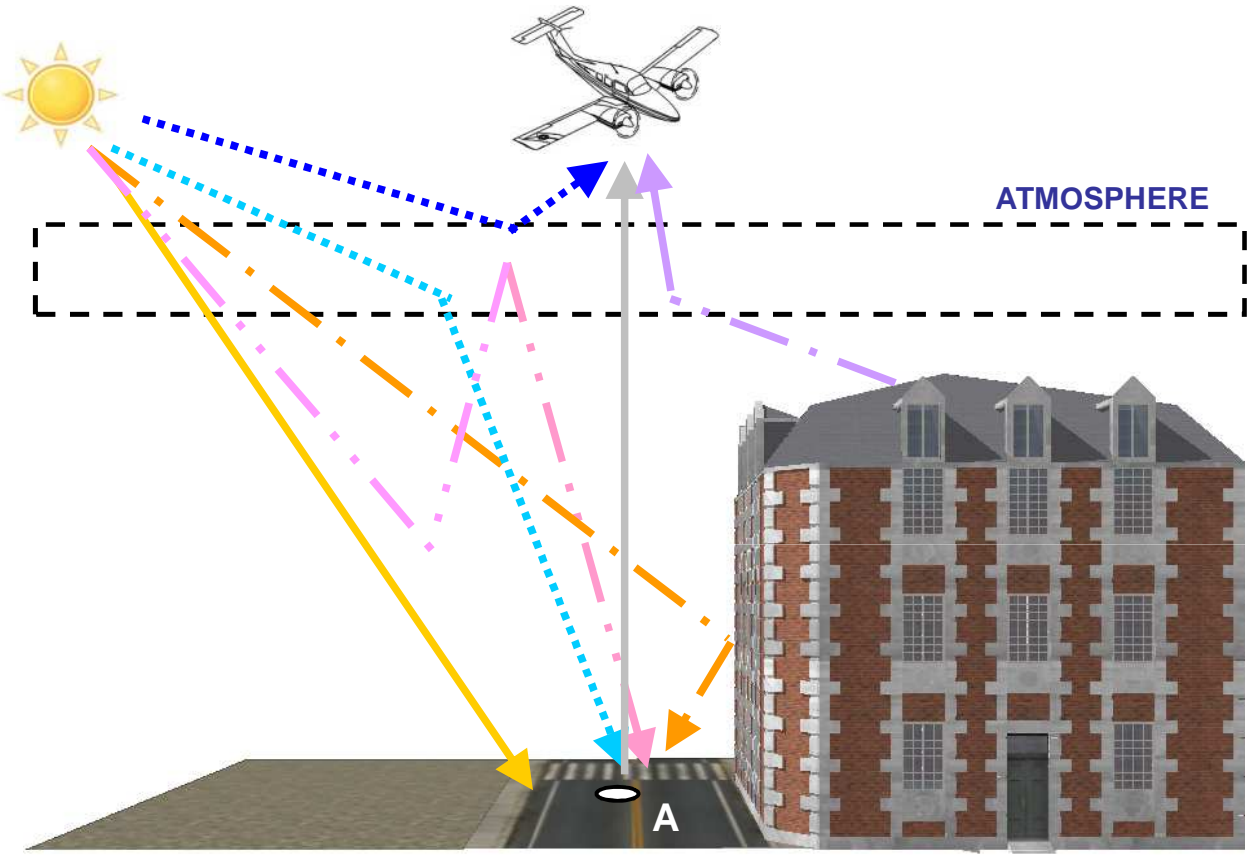

c) ICV

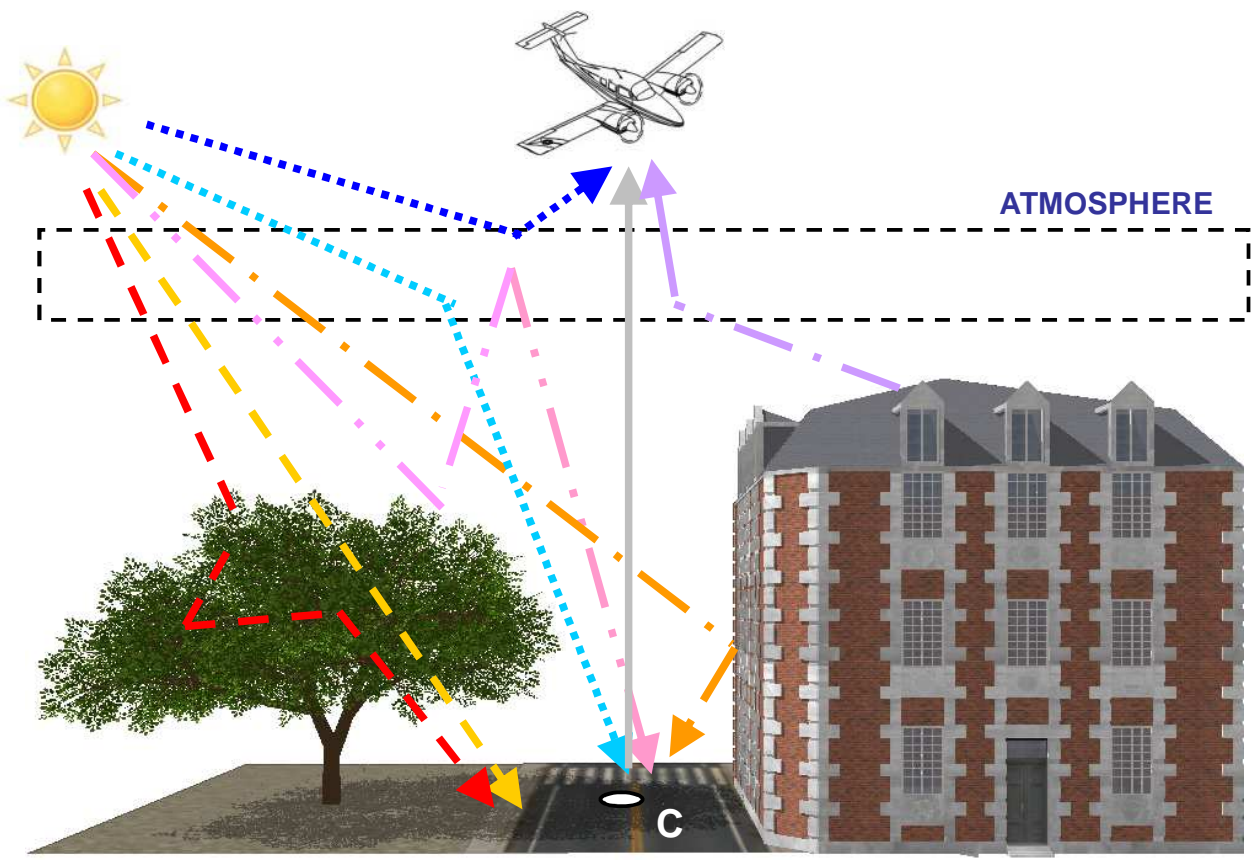

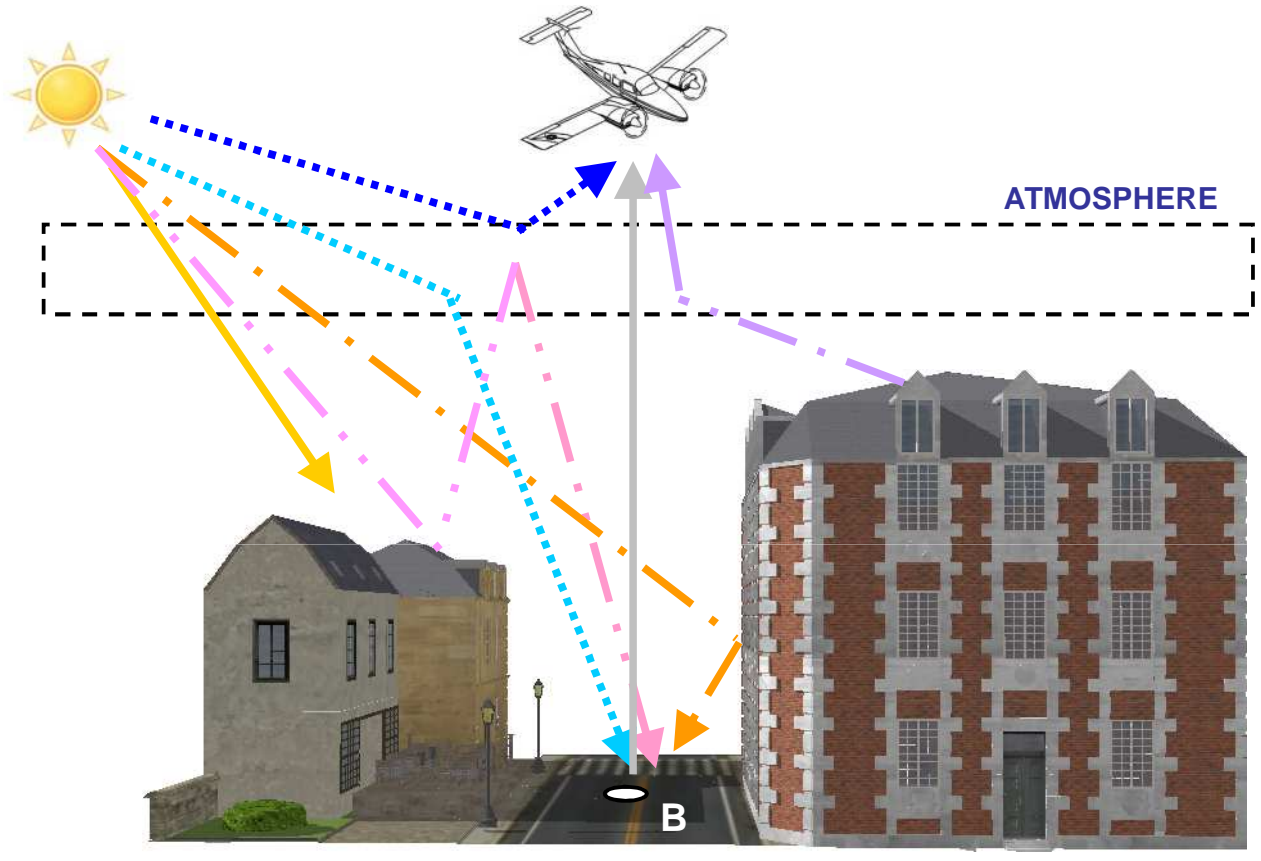

IRRADIANCES

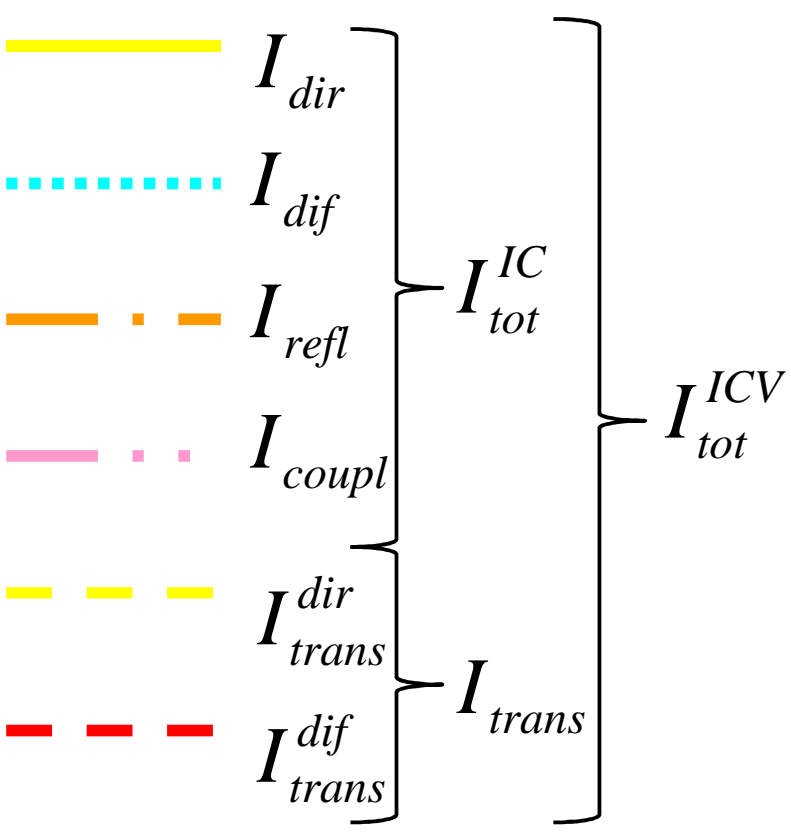

RADIANCES

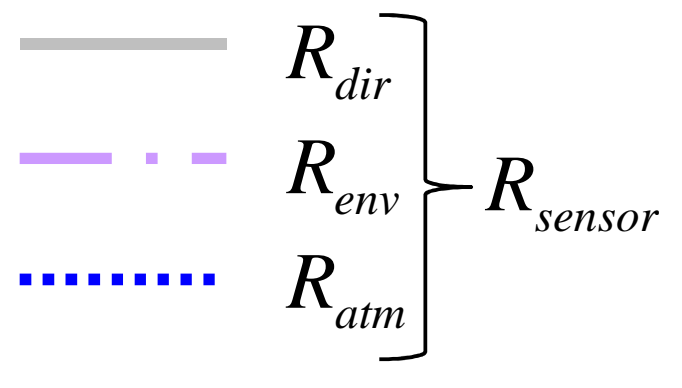




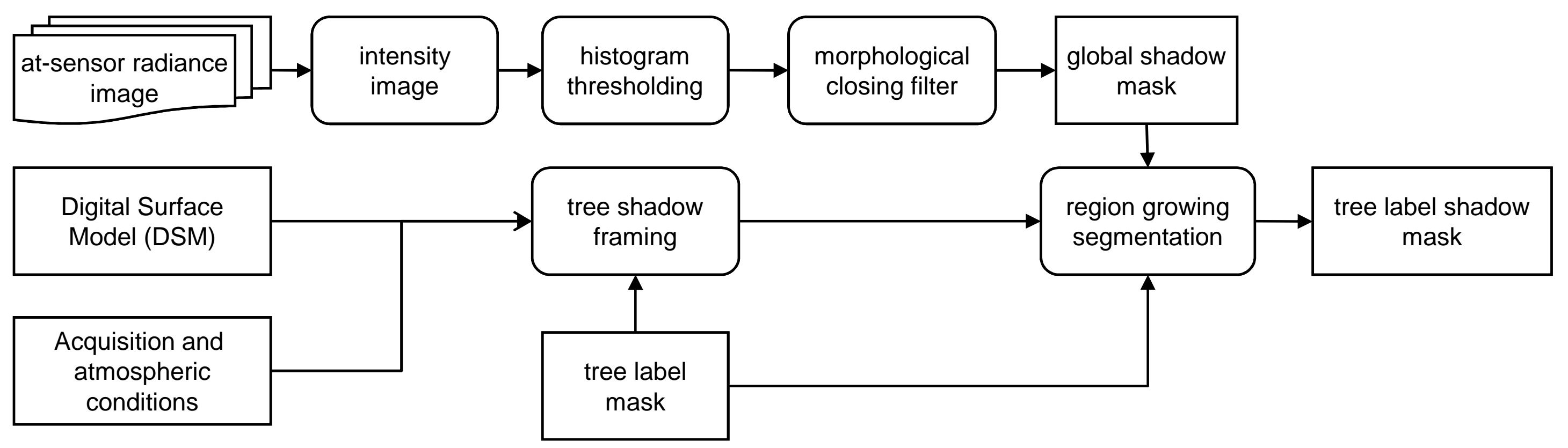




\section{a) upper view}
b) 3D view
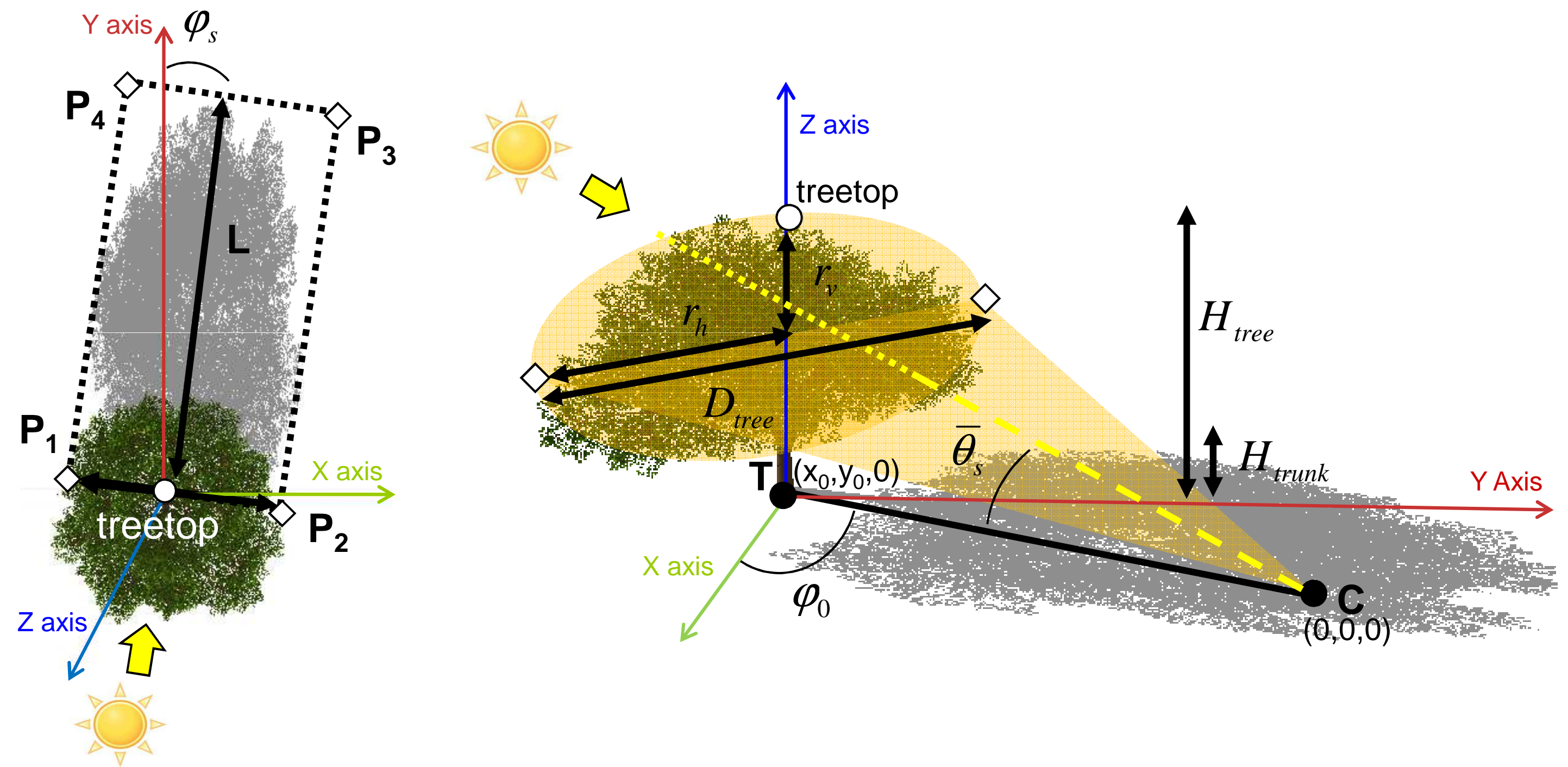
Mock-up modeling

(top view)

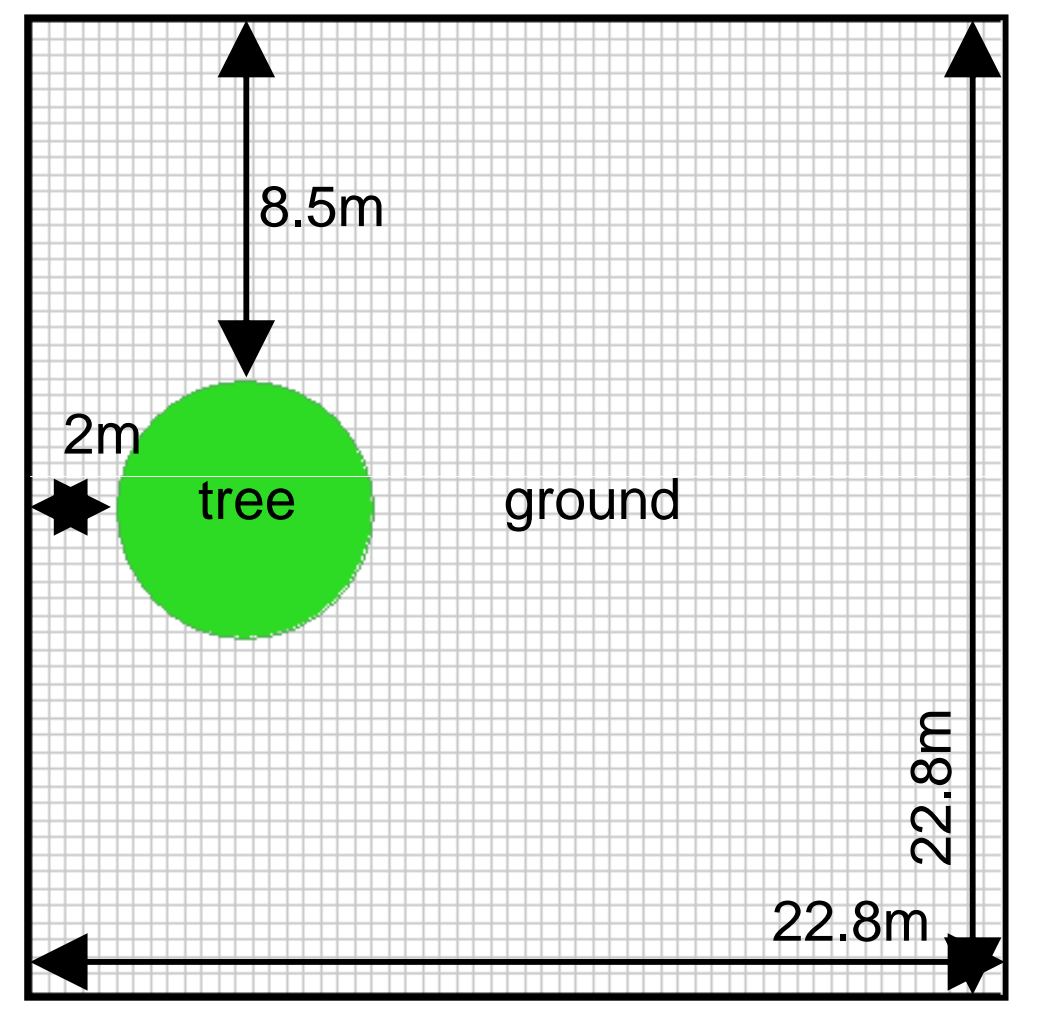

$\theta_{s}=\left[30^{\circ}, 45^{\circ}\right]$
Tree modeling

tree

height

$\left(H_{\text {tree }}\right)$

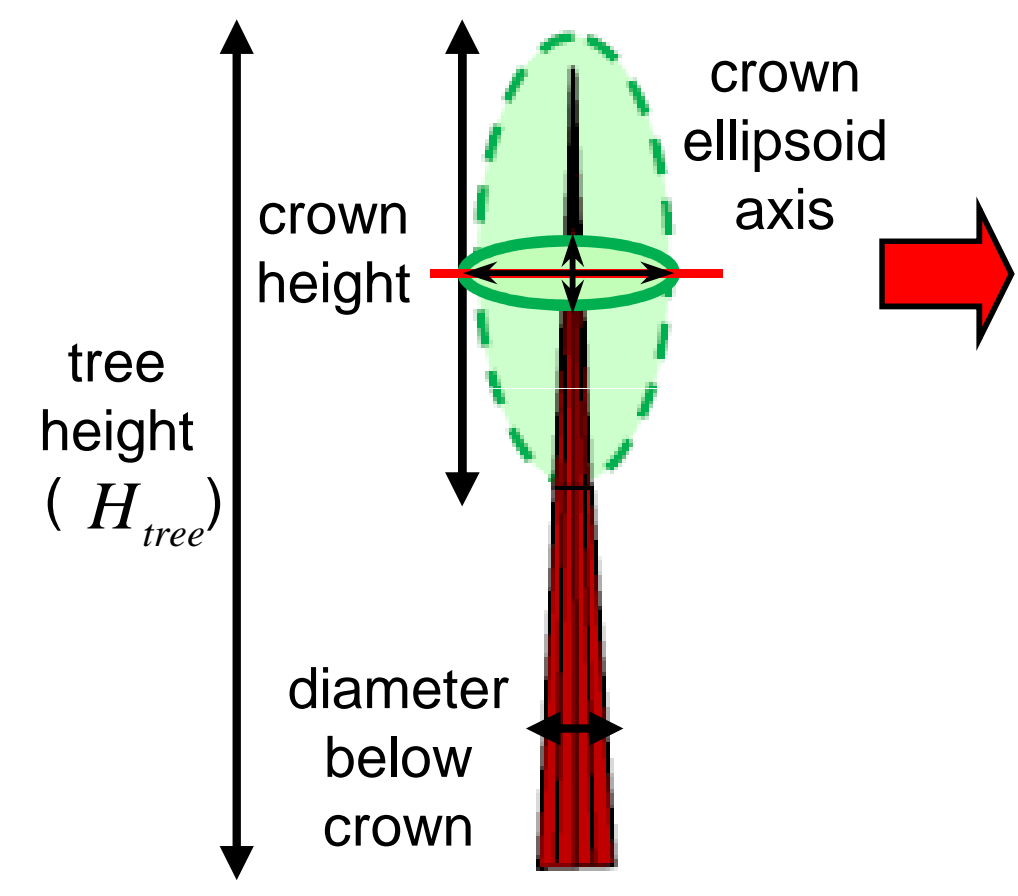

2D profile of the tree crown (turbid voxel representation)

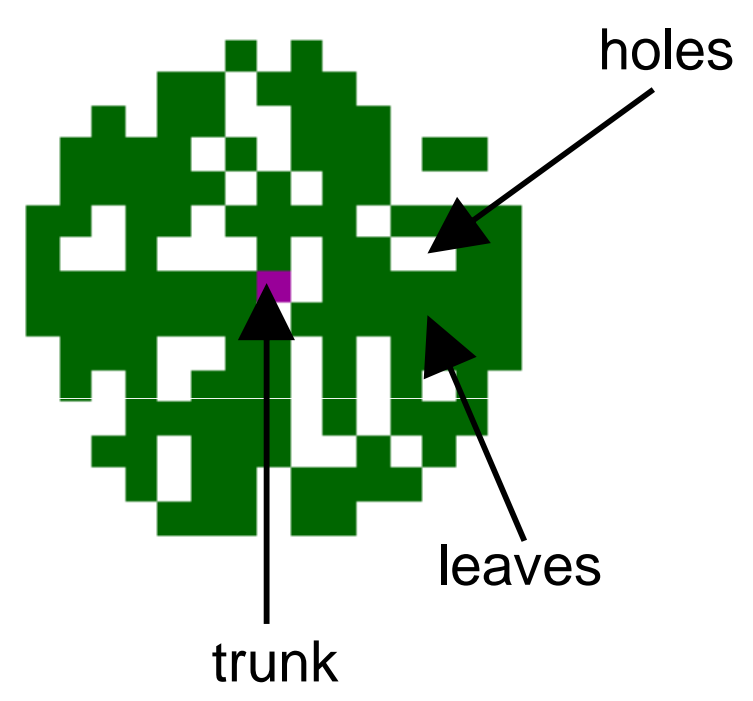




\section{Figure14a}

Click here to downdwasisFigure: Fig14a.pdf

asphalt
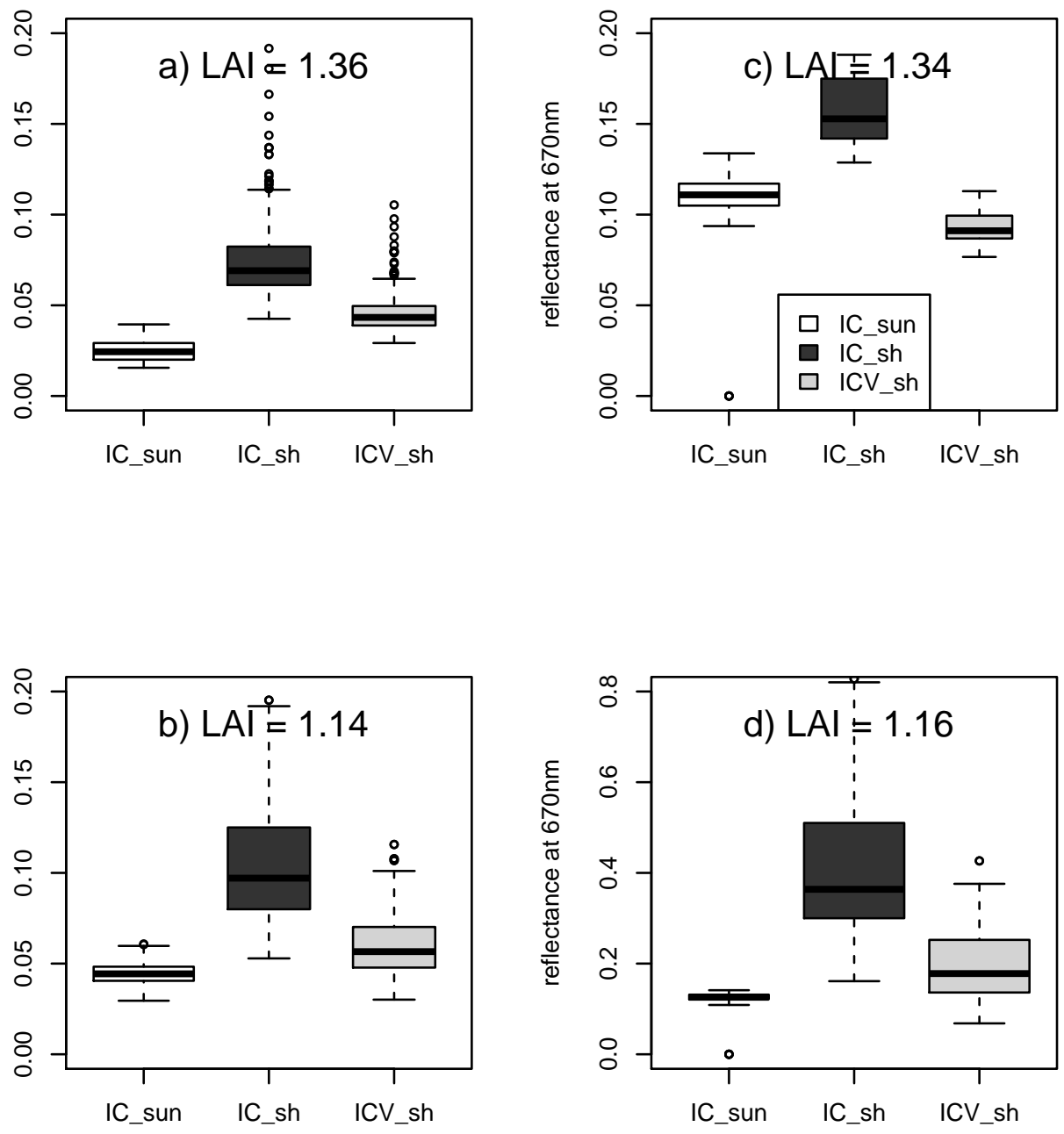

a) $L A I^{\circ}=1.36$

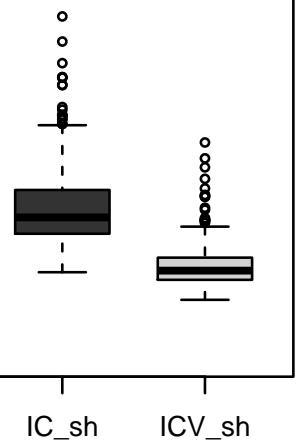

IC_sun IC_sh ICV_sh

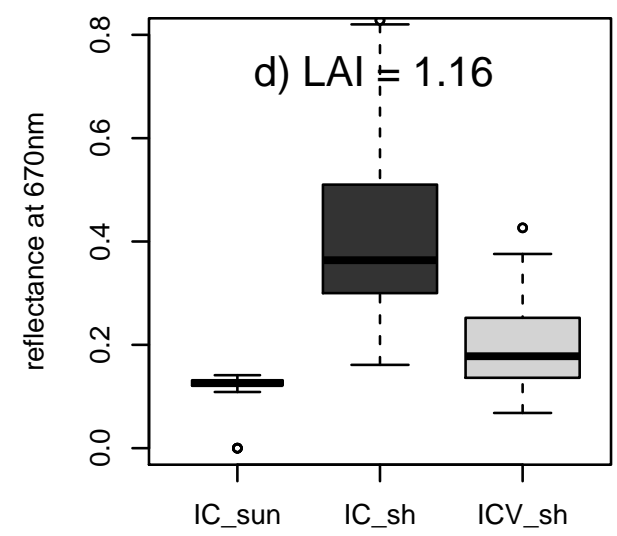

water
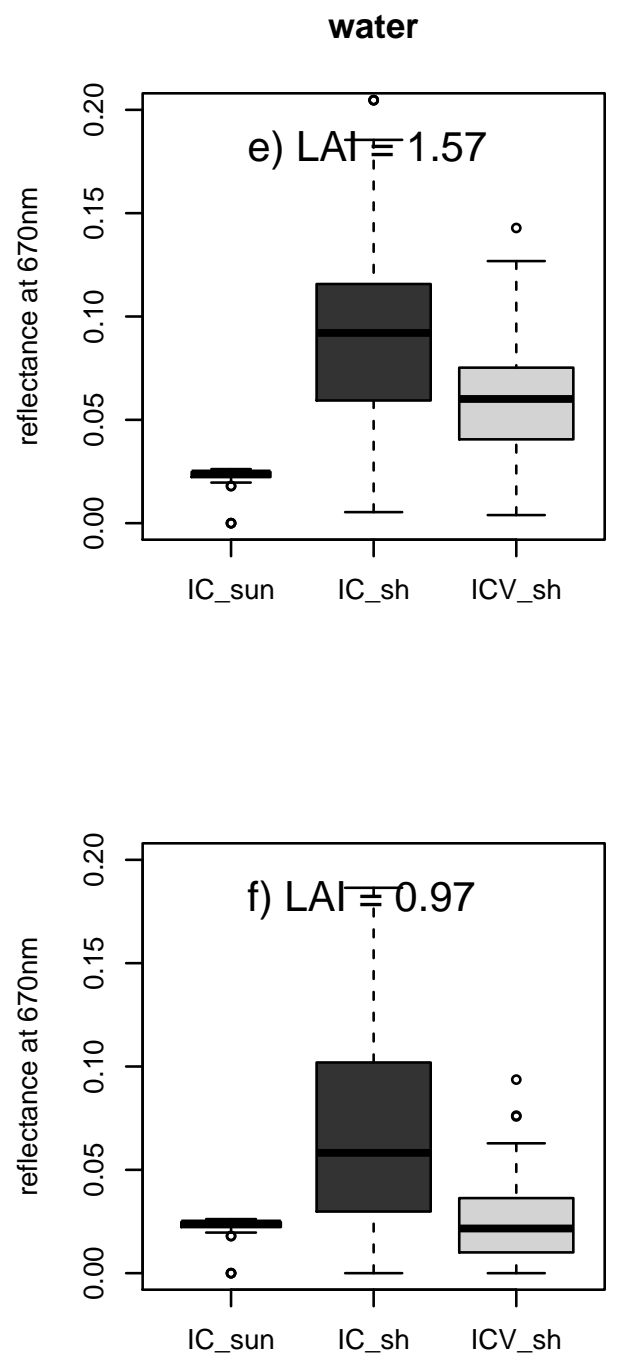

IC_sun 


\section{1}

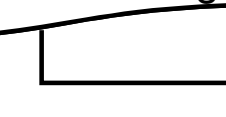

\section{reflectance hyperspectral} image

ICARE atmospheric correction

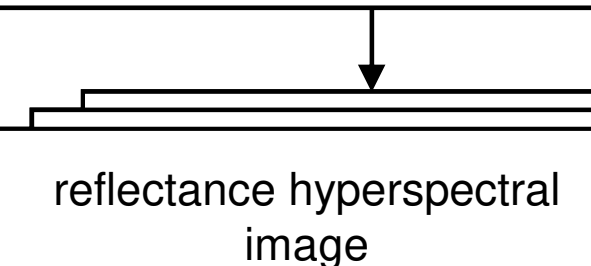

tree crown delineation

3.3

tree shadow detection

3.4

3.4.1. Reference correction factor $\left(\beta_{\text {ref }}\right)$

3.4.1.1. Design of experiments

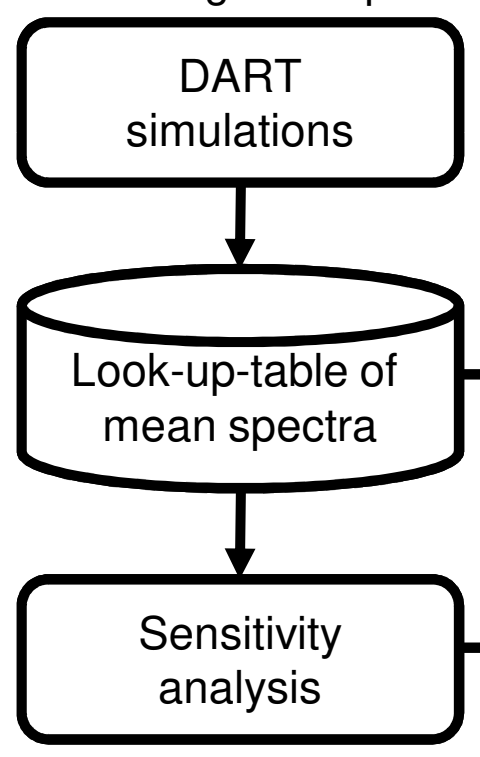

3.4.1.2. tree LAl estimation from empirical NDVI regression model

3.4.1.3. derivation of $\beta_{\text {ref }}$ from an empirical multivariate regression model

\subsubsection{Computation of tree viewing} solid angles $\left(\Omega\right.$ and $\Omega_{\text {ref }}$ ) 


\section{Figure}

Click here to download Figure: Fig8_revisednumber.pdf
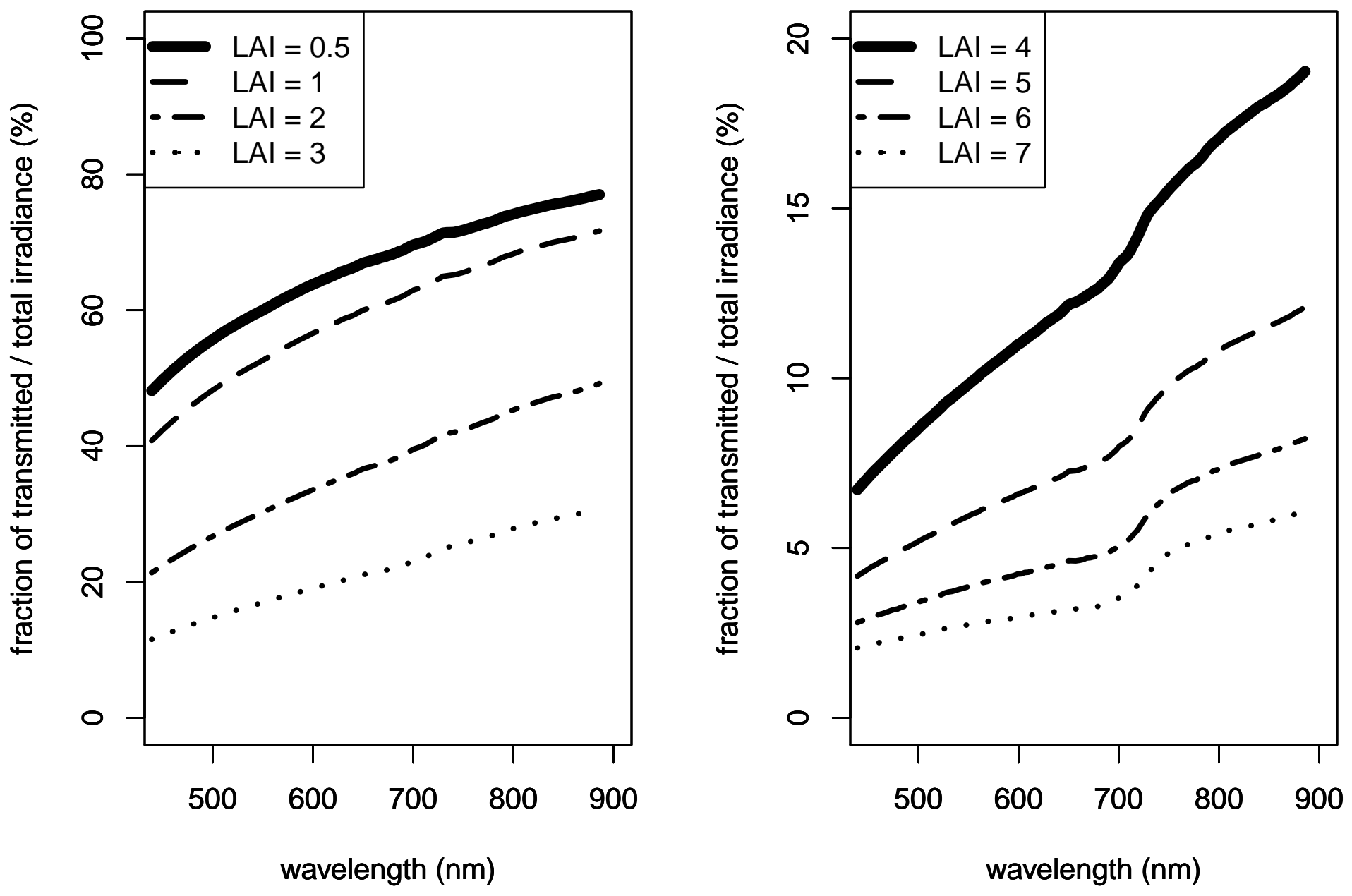

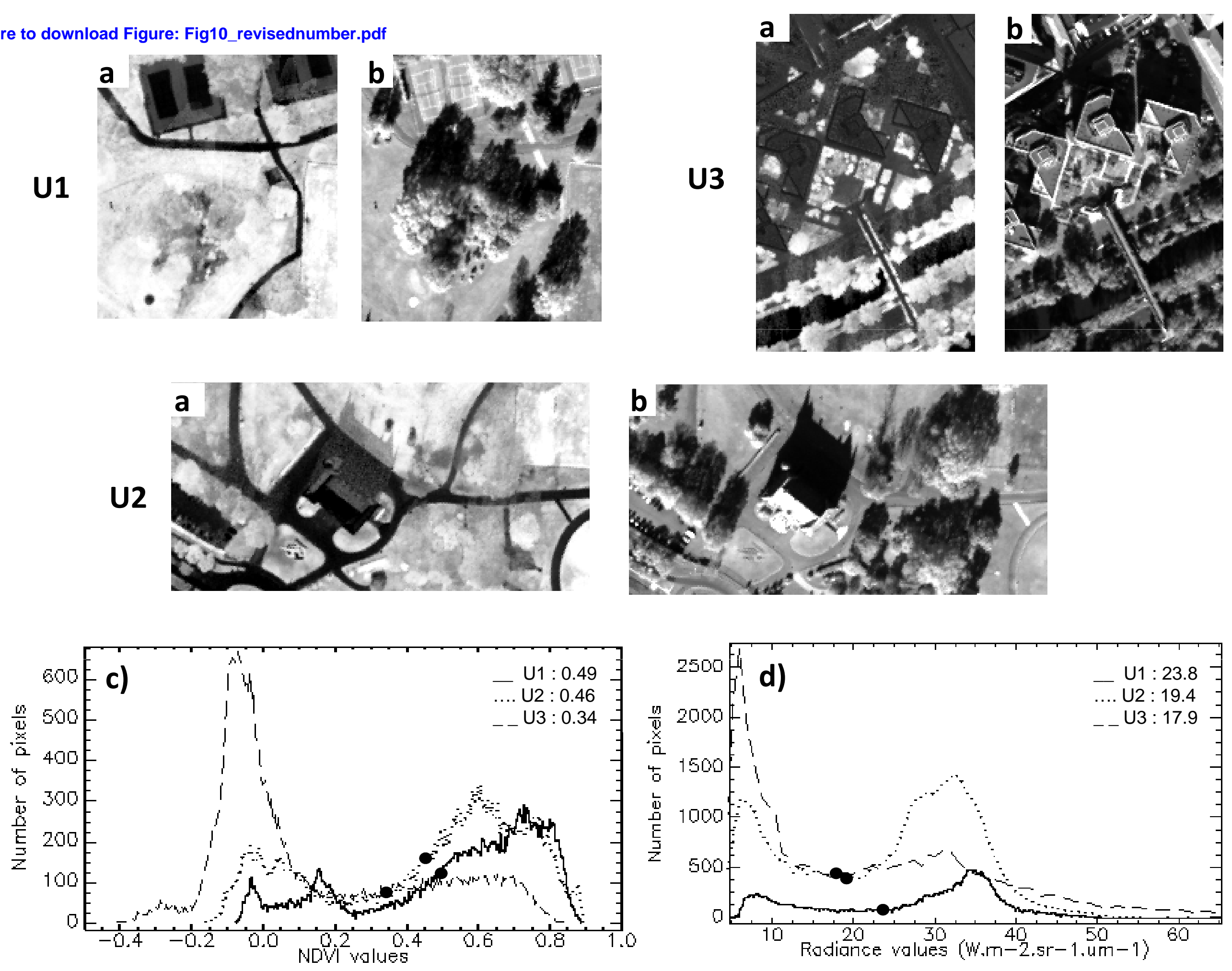

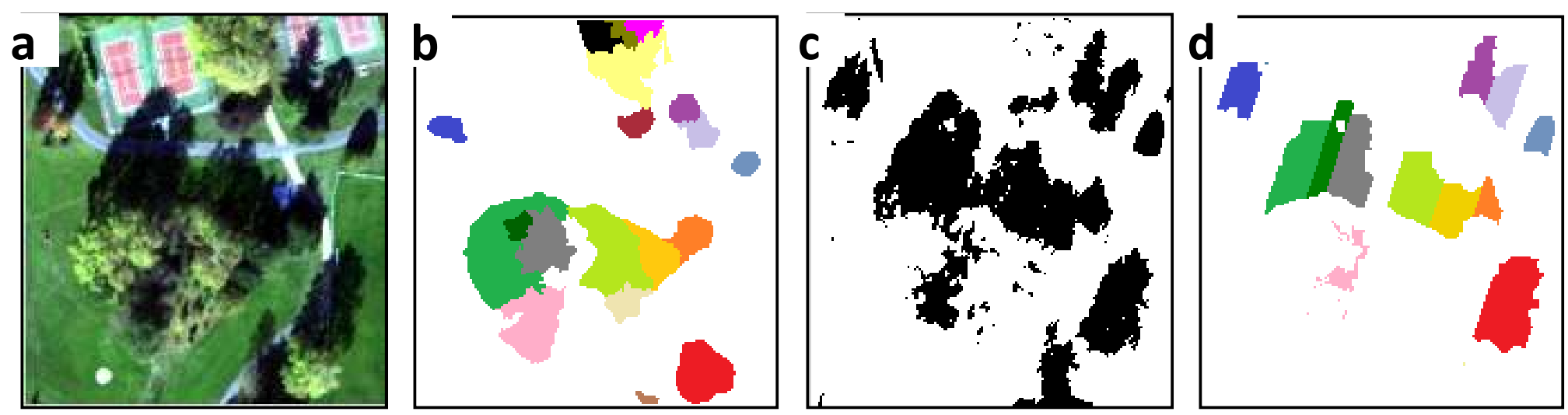

U2
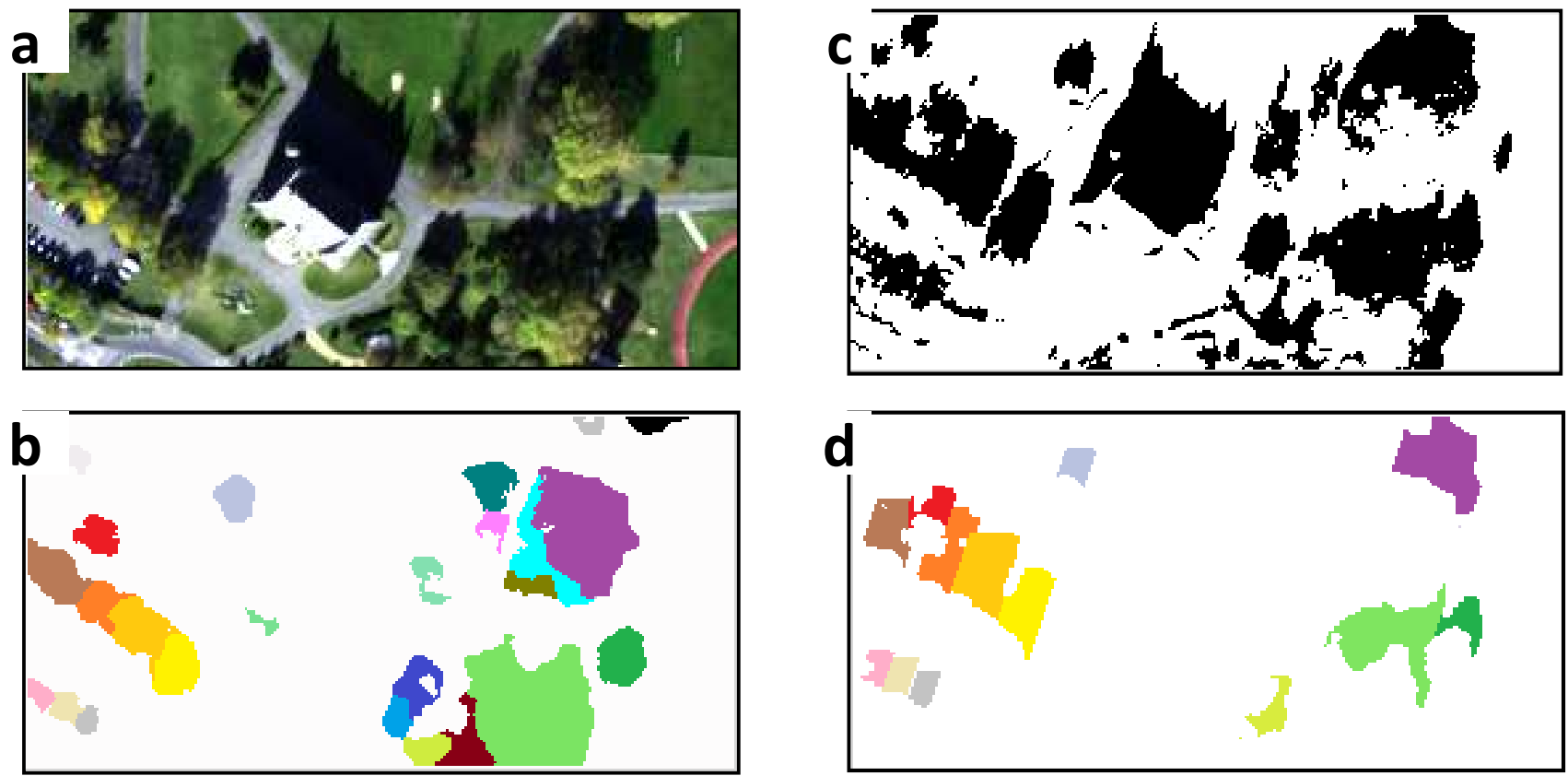

U3
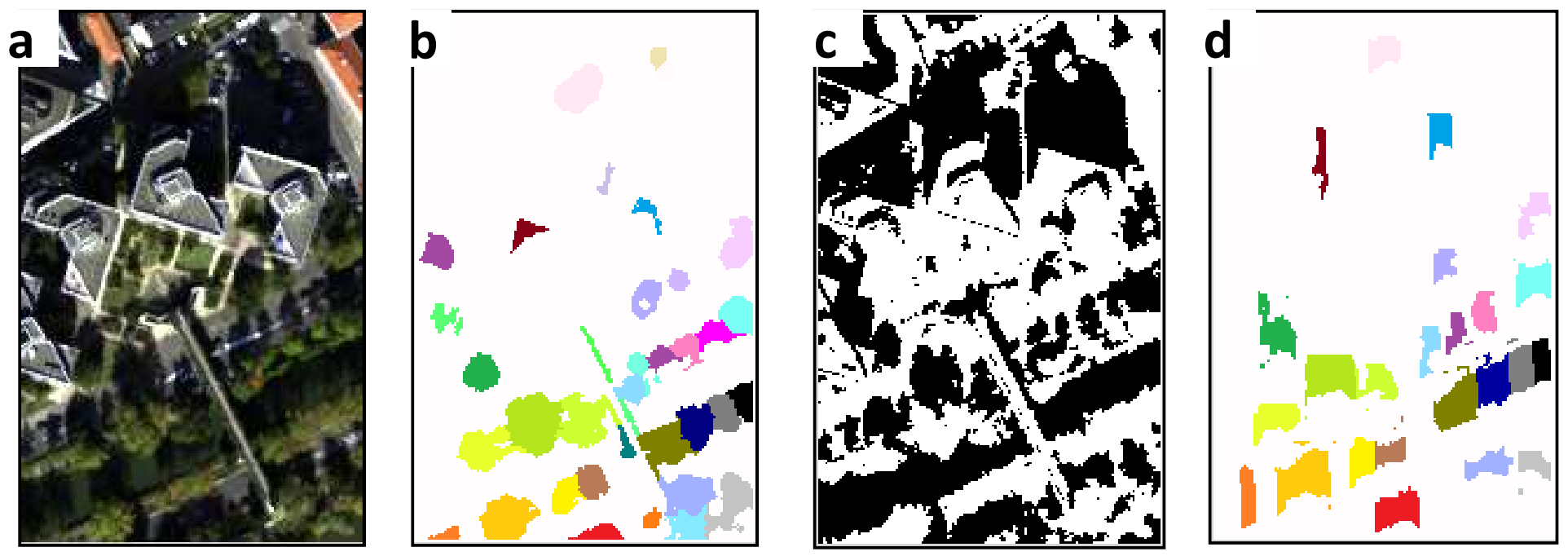
U1
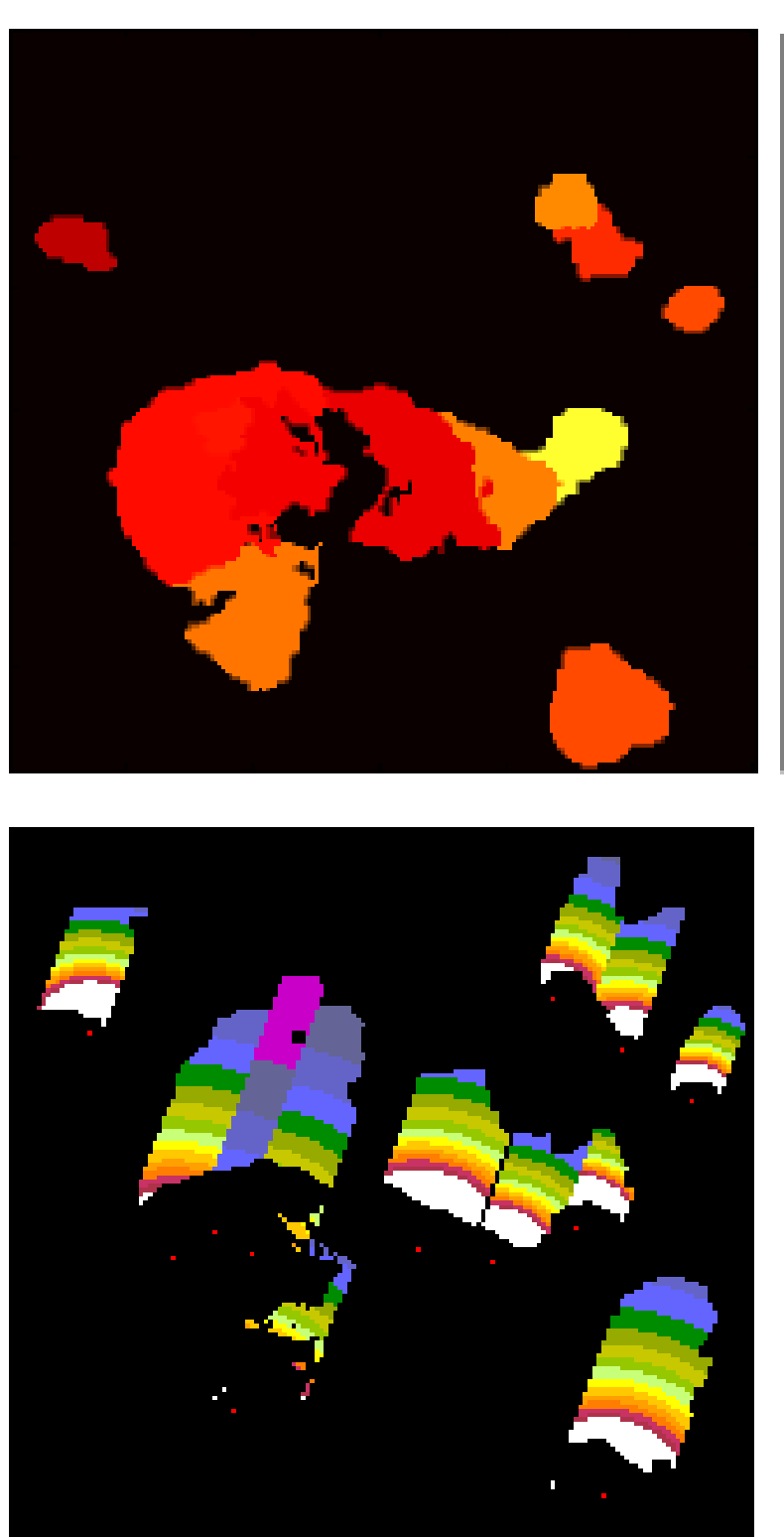

U2
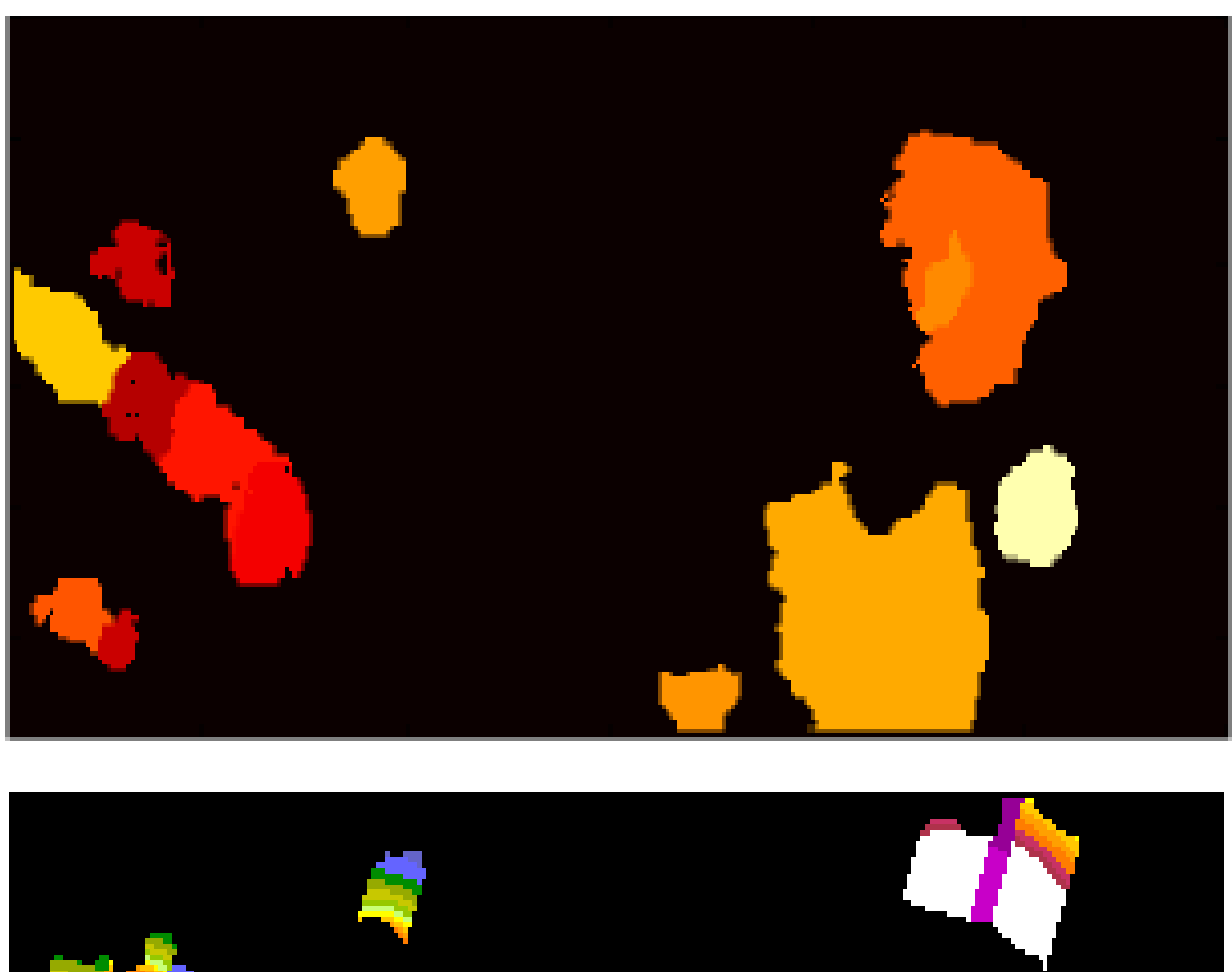

a
U3

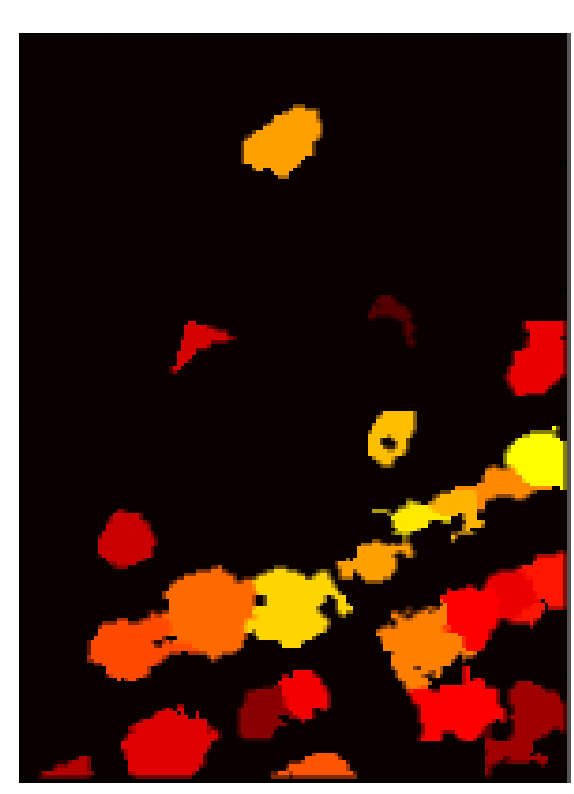

3.0

2.5

2.0

1.5

1.0

0.5

0

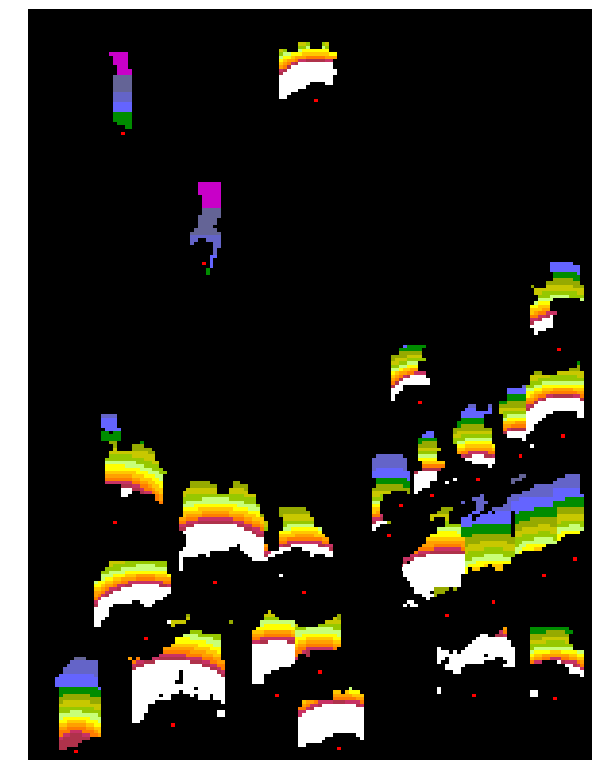

1.57

$(\pi / 2)$
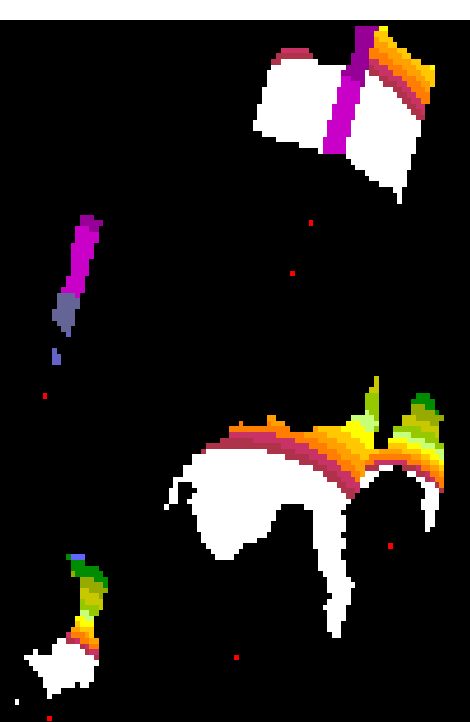

0.78 $(\pi / 4)$ 